\title{
Schwann Cells Sense and Control Acetylcholine Spillover at the Neuromuscular Junction by $\alpha 7$ Nicotinic Receptors and Butyrylcholinesterase
}

\author{
Konstantin A. Petrov, ${ }^{1,4,5}$ Emmanuelle Girard, ${ }^{1,3}$ Alexandra D. Nikitashina, ${ }^{1,2,4}$ Cesare Colasante, $, 1,9$ \\ Véronique Bernard, ${ }^{10}$ Leniz Nurullin, ${ }^{2,6}$ Jacqueline Leroy, ${ }^{1}$ Dmitry Samigullin, ${ }^{2}$ Omer Colak, ${ }^{1,7}$ Evgenii Nikolsky, ${ }^{2,5,6}$ \\ Benoit Plaud, ${ }^{1,8}$ and Eric Krejci ${ }^{1}$ \\ ${ }^{1}$ COGNAC G, Université Paris Descartes, CNRS, Service de Santé des Armées, UMR 8257, MD 4, 75006 Paris, France, ${ }^{2}$ Kazan Institute of Biochemistry and \\ Biophysics, Kazan 420111, Russia, ${ }^{3}$ Laboratoire de Biologie Moléculaire de la Cellule, CNRS UMR 5239/ENS Lyon, Université de Lyon, 69364 Lyon cedex 07 , \\ France, ${ }^{4}$ A.E. Arbuzov Institute of Organic and Physical Chemistry, Kazan 420088, Russia, ${ }^{5}$ Kazan Federal University, Kazan 420008, Russia, ${ }^{6}$ Kazan State \\ Medical University, Kazan 420012, Russia, ${ }^{7}$ Akdeniz University, Faculty of Engineering, 07058 Antalya, Turkey, ${ }^{8}$ Paris-Diderot University and Assistance \\ Publique Hôpitaux de Paris, Department of Anesthesiology and Surgical Critical Care, Hôpital Saint-Louis, 75475 Paris cedex 10, France, ${ }^{9}$ Laboratory of \\ Behavioral Physiology, Faculty of Medicine, University of Los Andes, Mérida 5101 Venezuela, and ${ }^{10}$ Neuroscience Paris Seine, Université Pierre et Marie \\ Curie UM CR 18, CNRS UMR 8246, INSERM U1130, 75005 Paris, France
}

Terminal Schwann cells (TSCs) are key components of the mammalian neuromuscular junction (NMJ). How the TSCs sense the synaptic activity in physiological conditions remains unclear. We have taken advantage of the distinct localization of acetylcholinesterase (AChE) and butyrylcholinesterase (BChE) at the $\mathrm{NMJ}$ to bring out the function of different ACh receptors (AChRs). AChE is clustered by the collagen $Q$ in the synaptic cleft and prevents the repetitive activation of muscle nicotinic AChRs. We found that $B C h E$ is anchored at the TSC by a proline-rich membrane anchor, the small transmembrane protein anchor of brain AChE. When BChE was specifically inhibited, ACh release was significant depressed through the activation of $\alpha 7 \mathrm{nAChRs} \mathrm{localized} \mathrm{on} \mathrm{the} \mathrm{TSC} \mathrm{and} \mathrm{activated} \mathrm{by} \mathrm{the} \mathrm{spillover} \mathrm{of} \mathrm{ACh.}$ When both AChE and BChE were inhibited, the spillover increased and induced a dramatic reduction of ACh release that compromised the muscle twitch triggered by the nerve stimulation. $\alpha 7 \mathrm{nAChRs}$ at the TSC may act as a sensor for spillover of ACh adjusted by BChE and may represent an extrasynaptic sensor for homeostasis at the NMJ. In myasthenic rats, selective inhibition of AChE is more effective in rescuing muscle function than the simultaneous inhibition of $\mathrm{AChE}$ and $\mathrm{BChE}$ because the concomitant inhibition of $\mathrm{BChE}$ counteracts the positive action of AChE inhibition. These results show that inhibition of BChE should be avoided during the treatment of myasthenia and the pharmacological reversal of residual curarization after anesthesia.

Key words: acetylcholinesterase; glia; muscle; neuromuscular disease; synaptic homeostasis

\section{Introduction}

Acetylcholinesterase (AChE) ends the action of acetylcholine $(\mathrm{ACh})$ in the cholinergic synapses and prevents the repetitive

\footnotetext{
Received Jan. 24, 2014; revised April 11, 2014; accepted April 30, 2014.

Author contributions: K.A.P., E.N., and E.K. designed research; K.A.P., E.G., A.D.N., C.C., V.B., L.N., J.L., D.S., and E.K. performed research; K.A.P., E.G., A.D.N., C.C., V.B., L.N., J.L., D.S., O.C., and E.K. analyzed data; K.A.P., E.N., B.P., and E.K. wrote the paper.

This work was supported by the Russian Government (Program of Competitive Growth of Kazan Federal University among World's Leading Academic (enters Grant to E.N.), the Russian Foundation Basic Research (Grant 12-0433296 to K.A.P.), and the AFMTelethon (E.K.). We thank Marc Abitbol and Philippe Ascher for critical reading of the paper and helpful discussions; Al-Shekhadat (Biomedical Center, St.Petersburg, Russia) for synthesis of peptide for EAMG induction; M. Skok (Palladin Institute of Biochemistry, Kiev, Ukraine) for the gracious gift of antibodies against $\alpha 7 \mathrm{nAChR}$; Géraldine Toutirais for managing the platform Service de Microscopie Électronique of the Institut de Biologie Paris-Seine (Université Pierre et Marie Curie, Paris) and Jean Maurice Petit for managing the platform Service Commun de Microscopie (Université Paris Descartes); and Uwe Maskos for providing the founder KO mice of $\alpha 7, \beta 2$, and $\beta 4 \mathrm{nAChRs}$.

The authors declare no competing financial interests.

Correspondence should be addressed to Eric Krejci, COGNAC G, CNRS UMR 8257, 45 rue des Saints Pères, 75006 Paris, France. E-mail: eric.krejci@parisdescartes.fr.

DOI:10.1523/JNEUROSCI.0329-14.2014

Copyright $\odot 2014$ the authors $\quad 0270-6474 / 14 / 3411870-14 \$ 15.00 / 0$
}

activation of acetylcholine receptors (AChRs). Therefore, AChE inhibitors are used to partially block the degradation of ACh and thus prolong its biological effect in different clinical conditions such as congenital myasthenic syndromes and myasthenia gravis (MG), which are characterized by a decrease of AChR density at the neuromuscular junction (NMJ; Vincent, 2010). In these diseases, the inhibition of AChE increases the half-life of ACh in the synaptic cleft and therefore the number of activated postsynaptic nAChRs. Anesthetists also use AChE inhibitors (e.g., neostigmine) in daily routine practice to reverse the action of nondepolarizing muscle relaxants (Srivastava and Hunter, 2009).

In addition to AChE, butyrylcholinesterase (BChE) is also abundant at the NMJ. AChE and BChE share many properties. BChE hydrolyzes ACh as well as AChE (Nicolet et al., 2003). $\mathrm{BChE}$ and $\mathrm{AChE}$ are organized in oligomers by the same associated proteins [collagen $\mathrm{Q}(\mathrm{ColQ})$ and proline-rich membrane anchor (PRiMA)]. ColQ is a collagen that anchors AChE in basal lamina. PRiMA is a small transmembrane protein that tethers at the plasma membrane (Massoulié et al., 2008). It is generally accepted that AChE plays the major role in the fast hydrolysis of 
ACh at NMJs, whereas BChE acts simply as a backup enzyme for AChE (Masson and Lockridge, 2010). However, some data support the idea that $\mathrm{BChE}$ and $\mathrm{AChE}$ have separate roles at the NMJ. $\mathrm{AChE}$ and $\mathrm{BChE}$ are localized in different sites at the NMJ. AChE is anchored in the synaptic cleft (Bernard et al., 2011), whereas $\mathrm{BChE}$ was assumed to be distributed around the terminal Schwann cell (TSC; Davis and Koelle, 1967). AChE and BChE seem to modulate differentially $\mathrm{ACh}$ release. It has been shown that the specific inhibition of $\mathrm{AChE}$ increases the ACh release through the activation of muscarinic receptors (Minic et al., 2002). On the contrary, the inhibition of both AChE and BChE decreases the probability of $\mathrm{ACh}$ release regardless of the muscarinic receptors (Minic et al., 2003).

The initial purpose of this study was to understand the specific function of BChE at the NMJ. Using a specific monoclonal antibody directed against mouse $\mathrm{BChE}$, we found that $\mathrm{BChE}$ is anchored by PRiMA at the surface of the TSC. At the NMJ, TSCs detect the nerve activity and modify the release of ACh (Auld and Robitaille, 2003). When BChE was specifically inhibited, we found a significant depression of ACh release that depended on $\alpha 7 \mathrm{nAChRs}$ localized on the TSC. The reduction of the release was dramatically accentuated when AChE was also inhibited. When a specific AChE inhibitor was used to increase ACh concentration in the synaptic cleft of myasthenic rats, the functional improvement was better than with a nonselective inhibitor of $\mathrm{AChE}$ and $\mathrm{BChE}$, during which the inhibition of $\mathrm{BChE}$ counteracted the positive action of AChE inhibition. These results show that $\mathrm{BChE}$ has a specific function at the $\mathrm{NMJ}$ and its inhibition may be counterproductive during the treatment of myasthenia and in anesthesia to reverse residual neuromuscular blockade.

\section{Materials and Methods}

Experiments. All experiments were performed following French guidelines for laboratory animal handling approved by the Animal Committee of Université Paris Descartes in accordance with the European Community Council Directive of February 1, 2013 (82010/63/EEC registration number CEEA34.EK/AGC/LB.111.12).

Endplate electrophysiology and threshold of muscle action potential generation. Hemidiaphragm nerve-muscle preparations were pinned in translucent chambers and perfused at a rate of $2-3 \mathrm{ml} / \mathrm{min}$ with oxygenated $\left(95 \% \mathrm{O}_{2}, 5 \% \mathrm{CO}_{2}\right)$ Ringer's-Krebs' solution containing the following (in mM): $135 \mathrm{NaCl}, 5 \mathrm{KCl}, 2 \mathrm{CaCl}_{2}, 1 \mathrm{MgCl}_{2}, 1 \mathrm{NaH}_{2} \mathrm{PO}_{4}, 15$ $\mathrm{NaHCO}_{3}$, and 11 glucose, pH 7.2-7.4. End Plate Potentials (EPPs) and miniature EPPs (mEPPs) were recorded in the synaptic zone using the standard microelectrode technique (3 $\mathrm{M} \mathrm{KCl}$, resistance $10-15 \mathrm{M} \Omega$ ) at $20-22^{\circ} \mathrm{C}$. Synaptic responses were recorded using an Axoclamp 900A amplifier and digitized using Digidata 1440A (Molecular Devices) with WinWCP software (John Dempster, University of Strathclyde, United Kingdom). To prevent muscle contractions, $\mu$-conotoxin GIIIB ( $2 \mu \mathrm{M}$; Peptide) was used.

To evaluate the threshold of nerve-evoked action potentials (APs), muscle preparations were incubated in $0.5 \mu \mathrm{M}$ D-tubocurarine (dTC) for $60 \mathrm{~min}$ and then continuously perfused by $3 \mu \mathrm{M}$ neostigmine and $0.2 \mu \mathrm{M}$ dTC throughout the recording period (Wood and Slater, 1995). The low concentration of dTC and the inhibition of cholinesterase allowed the recovery of the muscle AP generation in part of the muscle fibers. Contractions of diaphragm in these conditions remained very weak, which made possible intracellular recording by microelectrodes. We analyzed the events in which the rising phase of EPP and the rising phase of the AP triggered by this EPP can be mathematically separated (see Fig. 4C) to determine the threshold (in millivolts) precisely. Motor nerve was stimulated only one time in each muscle fiber. The resting membrane potential was $70-75 \mathrm{mV}$.

Immunolocalization at light microscopy. Isolated nerve-diaphragm preparations were stretched approximately to their resting length, pinned on Rhodorsil (Rhône-Poulenc)-lined Plexiglas chambers $(2 \mathrm{ml}$ volume), perfused with oxygenated Ringer's-Krebs' solution, and fixed with freshly prepared $4 \%$ paraformaldeyde (ElectronMicroscopy Sciences) in $0.01 \mathrm{M}$ PBS for $1 \mathrm{~h}$ at room temperature. After washing with PBS, the muscles were separated in two groups: (1) hemidiaphragm muscles were immersed in 20-40\% sucrose in PBS, frozen in isopentane at $-40^{\circ} \mathrm{C}$, and transverse sections were obtained with a cryostat at $10 \mu \mathrm{m}$ and (2) muscle fibers from the other hemidiaphragm muscles were teased apart. Excess aldehyde groups were reduced with $50 \mathrm{~mm}$ glycine (Sigma-Aldrich) in PBS solution for $30 \mathrm{~min}$ and blocked against nonspecific binding with 5\% normal goat serum (Sigma-Aldrich) in PBS for 30 min. BChE was detected in muscle fibers after overnight incubation at $4^{\circ} \mathrm{C}$ with anti-BChE biotinylated monoclonal antibody $4 \mathrm{H} 1$ at $1 \mu \mathrm{g} / \mathrm{ml}$ (1:1000) in PBS supplemented with $1 \%$ normal goat serum. $\alpha 7 \mathrm{nAChRs}$ were detected in muscle fibers after overnight incubation at $4^{\circ} \mathrm{C}$ with anti- $\alpha 7$ biotinylated polyclonal antibody at $1 \mu \mathrm{g} / \mathrm{ml}$ (1:1000) in PBS supplemented with $1 \%$ normal goat serum. S-100 was detected after overnight incubation at $4^{\circ} \mathrm{C}$ with anti-S-100 biotinylated polyclonal antibody (Abcam) at $1 \mu \mathrm{g} / \mathrm{ml}(1: 1000)$ in PBS supplemented with $1 \%$ normal goat serum. BChE was revealed by $1 \mathrm{~h}$ incubation at room temperature with Alexa Fluor 594-conjugated-streptavidin (Vector Laboratories). $\alpha 7 \mathrm{nAChR}$ was revealed by $1 \mathrm{~h}$ incubation at room temperature with AttoN-647-conjugated streptavidin (1:1000; Invitrogen). S-100 was revealed by $1 \mathrm{~h}$ incubation at room temperature with Alexa Fluor-350-conjugated streptavidin (1:1000; Invitrogen). AChRs were stained with Alexa Fluor 488 or Alexa Fluor 647-conjugated $\alpha$-bungarotoxin (Invitrogen) in PBS and mounted with Vectashield antifade mounting medium (Vector Laboratories). A third group of ex vivo unfixed diaphragm muscles were immunolabeled for BChE by incubation for $1 \mathrm{~h}$ with biotinylated $4 \mathrm{H} 1$ at $2 \mu \mathrm{g} / \mathrm{ml}$ (1:500), fixed with $4 \%$ paraformaldehyde for $1 \mathrm{~h}$, and processed as described at the begining of this paragraph except for glycine incubation.

NMJs were analyzed using a LSM 510 META microscope (Carl Zeiss), mounted on an inverted microscope, and controlled through the manufacturer-supplied software and workstation. Images were collected using an oil-immersion objective [Plan-Apochromat $\times 63 / 1.2$ numerical aperture (NA)]. The pinhole aperture was set to 1 Airy unit. Images were digitized at 12 - or 16 -bit resolution into $512 \times 512$ or $1024 \times 1024$ pixel arrays. Data were analyzed using Zen 2008 software on a series of "lookthrough" projections of average intensity.

Immunolocalization by EM. After perfusion-fixation, as described in Immunolocalization at light microscopy, muscle fibers were incubated in $4 \%$ normal horse serum (NHS) for $30 \mathrm{~min}$ and then with $4 \mathrm{H} 1$ antibody $(0.5 \mu \mathrm{g} / \mathrm{ml})$ supplemented or with $30 \mathrm{~nm}$ biotinylated $\alpha$-BTX (Invitrogen) with $1 \%$ NHS at room temperature overnight. After washing, biotin was detected using streptavidin coupled to gold particles $(1.4 \mathrm{~nm}$ in diameter, 1:100 in PBS/BSA; Nanoprobes) for $2 \mathrm{~h}$. The fibers were then washed and postfixed in $1 \%$ glutaraldehyde for $10 \mathrm{~min}$. After washing in acetate buffer $(0.1 \mathrm{M}, \mathrm{pH} 7)$, immunogold particles were amplified using a silver enhancement kit (HQ silver; Nanoprobes) with a 3 min incubation at room temperature in the dark. After treatment of sections with $1 \%$ osmium, dehydration, and embedding in resin, ultrathin sections were cut, stained with lead citrate, and examined in an electron microscope (EM 912 OMEGA; Zeiss) equipped with a LaB6 filament at $80 \mathrm{kV}$ and images were captured with digital camera (SS-CCD, $2 \mathrm{kx} 2 \mathrm{k}$; Veleta).

Biochemical analysis of BChE molecular forms. Frozen muscles were disrupted through high-speed shaking (TissueLyser; QIAGEN) in $2 \mathrm{ml}$ plastic tubes containing 2 stainless steel beads ( $5 \mathrm{~mm}$; QIAGEN) and 5 volumes of cold extraction buffer (10 mм HEPES, pH 7.2, $0.8 \mathrm{M} \mathrm{NaCl}, 1 \%$ CHAPS, 10 mм EDTA, 2 mm benzamidine). The extract was mixed thoroughly on a vortex mixer at $4^{\circ} \mathrm{C}$ for $10 \mathrm{~min}$ and then centrifuged at $4^{\circ} \mathrm{C}$ for $10 \mathrm{~min}$ at $20,000 \times \mathrm{g}$. BChE molecular forms were separated in 5-20\% sucrose gradients containing 10 mM HEPES, pH 7.4, $0.8 \mathrm{M} \mathrm{NaCl}$, $10 \mathrm{~mm}$ EDTA, $0.2 \%$ Brij 97, or 1\% CHAPS. Brij 97 was added to each sample (final concentration $0.2 \%$ ) before loading on the gradient. The gradients were centrifuged in a SW41 rotor for $18 \mathrm{~h}$ at 37,000 rpm and $\sim 48$ fractions were collected. Positions of internal sedimentation standards ( $\beta$-galactosidase, $16 \mathrm{~S}$; alkaline phosphatase, $6.1 \mathrm{~S}$ ) were used to convert fraction numbers to $S$ values. BChE activity was evaluated by the 
hydrolysis of $1 \mathrm{~mm}$ butyrylthiocholine in the presence of $1 \mathrm{~mm} \mathrm{DTNB}$ and of $10^{-6} \mathrm{M}$ BW284C51.

Ex vivo twitch tension measurements. Left hemidiaphragm muscles with their associated phrenic nerves were isolated from mice killed by dislocation of the cervical vertebrae followed by immediate exsanguination. Hemidiaphragms were mounted in a temperature-regulated ( $32 \pm$ $1^{\circ} \mathrm{C}$ ) chamber and bathed in oxygenated Ringer's-Krebs' solution. For twitch tension measurements, the central tendon of the hemidiaphragm muscle was tied by a stainless steel rod via a linen thread hook to a force sensor (UF1; LCM Systems) and the ribs were blocked with two long hooks. The train-of-four (TOF) responses ( $2 \mathrm{~Hz}$ for $2 \mathrm{~s}$ ) were evoked by stimulating the phrenic nerve via two microelectrodes with supramaximal current pulses of $0.1 \mathrm{~ms}$ duration. For each preparation, the resting tension was adjusted at the beginning of the experiment (to obtain maximal contractile response) and was monitored during the duration of the experiment. Signals from the force sensor were recorded and analyzed digitally, using PowerLab system and LabChart 6 software (ADInstruments).

MG animal model. An experimental autoimmune model of MG was produced according to the following protocol (Baggi et al., 2003). Female rats 6-8 weeks of age were immunized twice (1 month intervals) by subcutaneous administration of the peptide (DGDFAIVKFTKVLLDYTGHI) mixed in Freund's complete adjuvant (first injection) and incomplete (second injection). The development of muscle weakness was diagnosed in vivo by the marked decrement of surface electromyogram amplitude (i.e., integral AP) of hindlimb muscles. Under urethane anesthesia (1.2 g/kg, i.p.), the sciatic nerve was stimulated $(40 \mathrm{~Hz}$, train of 200 stimuli) in the femoral part and the integral muscle action potential from posterior surface of the lower leg was recorded by skin electrodes. The integral muscle action potential was recorded using an FE132 amplifier (ADInstruments) and digitized with the PowerLab4/35 system (ADInstruments). Ambenonium and bambuterol were delivered intraperitoneally dissolved in $\mathrm{H}_{2} \mathrm{O}$. Ambenonium was chosen as the AChE inhibitor because it contains quaternary nitrogen atoms and therefore does not cross the blood-brain barrier. It was important to limit the effects of brain AChE inhibition.

Calcium imaging of mammalian TSCs. Experiments were performed at room temperature on mouse levator auris longus (LAL) nerve-muscle preparations. Muscles were removed under deep anesthesia with ether. LALs were incubated in oxygenated Ringer's-Krebs' solution (see endplate electrophysiology methods) containing $20 \mathrm{~mm}$ fluo-3 AM (Invitrogen), $0.02 \%$ pluronic acid (Invitrogen), and $0.5 \%$ dimethylsulfoxide (Sigma) for $60 \mathrm{~min}$ at $20^{\circ} \mathrm{C}$ temperature. Partial chelation of heavy metal ions was achieved by $20 \mathrm{~mm}$ tetrakis (2-pyridylmethyl) ethylenediamine (Invitrogen) to limit the binding of these ions to fluo-3 (Rochon et al., 2001). After this loading procedure, the preparation was washed with Ringer'sKrebs' solution for $15 \mathrm{~min}$. Muscles were then pinned down in a recording chamber coated with Sylgard. Changes in fluorescence $(F)$ intensity were monitored using a confocal microscope (TCS SP5; Leica) equipped with an argon ion laser. Observations were performed using a $20 \times$ waterimmersion lens ( $1.00 \mathrm{NA}$; Leica). The $488 \mathrm{~nm}$ laser line was attenuated to $6 \%$ intensity and a long-pass filter with cutoff at $515 \mathrm{~nm}$ was used to detect the emitted $F$. Surface NMJs were located using the transmitted light channel of the confocal microscope. $F$ intensity was measured over the area of the TSC cell body and the relative changes in $F$ intensity were evaluated as a percentage as follows: $\Delta F / F=\left(F-F_{0}\right) / F_{0} \times 100$. Stimulation of the distal end of the cut motor nerve $(20 \mathrm{~Hz}, 120 \mathrm{~s})$ was achieved using a suction electrode. To prevent muscle contractions evoked by transmitter release, we used $\mu$-conotoxin GIIIB ( $2 \mu \mathrm{M}$; Peptide). If the calcium waves were triggered in a TSC by a burst of nerve stimulations $(20 \mathrm{~Hz}, 120 \mathrm{~s})$, the preparations were allowed to rest for $30 \mathrm{~min}$ for recovery with or without methyllycaconitine (MLA) (10 nM) to specifically block $\alpha 7 \mathrm{nAChR}$ ); then, a second burst of nerve stimulations $(20 \mathrm{~Hz}, 120 \mathrm{~s})$ was applied and the $F$ intensity was measured.

Data analysis. In all cases, data are reported as mean \pm SEM and $n$ indicates the number of end plates measured in each group. Two-group comparisons were performed using paired or unpaired Student's $t$ test. Differences between two groups were considered statistically significant at the probability level of $p<0.05$.
Chemicals. Tetraisopropyl pyrophosphoramide (iso-OMPA), atropine monohydrate sulfate, MLA, neostigmine methylsulphate bromide, and bambuterol hydrochloride were all from Sigma-Aldrich. Ambenonium dichloride was from Santa Cruz Biotechnology. $\mu$-conotoxin GIIIB was from Peptide. The solution of fluorocitrate (FC) was prepared as described previously (Bonansco et al., 2011): $8 \mathrm{mg}$ of the barium salt of DL-fluorocitric acid (Sigma) was dissolved in $0.1 \mathrm{M} \mathrm{HCl}$, precipitated by the addition of $0.1 \mathrm{M} \mathrm{Na}_{2} \mathrm{SO}_{4}$, buffered with $0.1 \mathrm{M} \mathrm{Na}_{2} \mathrm{HPO}_{4}$, and centrifuged at $1000 \times g$ for $5 \mathrm{~min}$. The supernatant containing FC was added to Ringer's buffer at a final concentration of $0.2 \mathrm{~mm}, \mathrm{pH} 7.2-7.4$.

\section{Results}

BChE is mainly anchored by PRiMA at the plasma membrane at the surface of the TSC

The first experimental step was to determine the accurate localization of $\mathrm{BChE}$ at the NMJ. In recent experiments using BChE enzymatic staining in AChE KO mice, BChE was mainly detected in the depth of the NMJ folds that invaginate within the muscle fibers (Blondet et al., 2010), whereas in previous experiments, BChE staining has been localized at the surface of mouse TSCs (Davis and Koelle, 1967). The spatial resolution of the BChE staining based on acetylthiocholine iodine hydrolysis is far from being optimal because it is affected by numerous parameters susceptible to altering the position of the precipitates observed. Indeed, the precipitates obtained can migrate somewhat haphazardly depending upon the experimental conditions. To circumvent this limitation, we used a monoclonal antibody $(4 \mathrm{H} 1)$ directed against mouse $\mathrm{BChE}$ that was produced specifically by immunization of $\mathrm{BChE} \mathrm{KO}$ mice with recombinant mouse $\mathrm{BChE}$. This antibody reveals unequivocally that BChE is abundantly localized at the NMJ (Mrvova et al., 2013). To analyze the distribution of BChE, we looked for colocalization of $4 \mathrm{H} 1$ with S100, a specific marker of TSCs (Reynolds and Woolf, 1992). We found a colabeling of BChE with S100, but not with $\alpha$-bungarotoxin, a well known antagonist of nAChRs (Fig. 1A). To further explore the BChE distribution, we used mice expressing membrane-anchored GFP in motoneurons (De Paola et al., 2003). The triple labeling of BChE with $4 \mathrm{H} 1$ (red), muscle nAChR with $\alpha$-bungarotoxin (blue), and nerve with GFP (green) revealed that $\mathrm{BChE}$ is localized mainly on the surface of the TSC at the membrane (Fig. 1A).

A known anchoring mechanism of AChE and BChE at the cell surface involves the small transmembrane protein PRiMA. In PRiMA KO mice, AChE is not found at the surface of central cholinergic neurons, but rather is retained into the endoplasmic reticulum (Dobbertin et al., 2009). To determine the accurate localization of BChE at the TSC, we incubated in to to nonpermeabilized diaphragms of WT and PRiMA KO mice with the $4 \mathrm{H} 1$ monoclonal anti-BChE antibody and found a strong labeling in WT, but not in PRiMA KO mice (Fig. $1 B$ ). In contrast, in permeabilized muscle sections, $4 \mathrm{H} 1$ labels BChE in both WT and PRiMA KO mice (Fig. 1B). To further prove the anchoring of BChE by PRiMA at the surface of the TSC, we analyzed the distribution of $\mathrm{BChE}$ with $4 \mathrm{H} 1$ at the NMJ in the tibialis anterior (TA) muscle at the EM level. As illustrated in Figure $2 \mathrm{~A}, 4 \mathrm{H} 1$ labeled WT and PRiMA KO NMJ in TA, as in the diaphragm. At the EM level, gold-labeled streptavidin was used to visualize biotinylated $4 \mathrm{H} 1$. Immunoparticles were localized along the surface of membrane in extensions close to the nerve terminal and at the cell body close to the NMJ (Fig. 2B). In contrast, in PRiMA KO mice, immunoparticles were absent from the plasma membrane of TSCs (membranes close to the nerve and close to the cell body (Fig. 2C), but were abundant in intracellular compartment close to the nucleus of cells in close proximity of the NMJ. Altogether, 

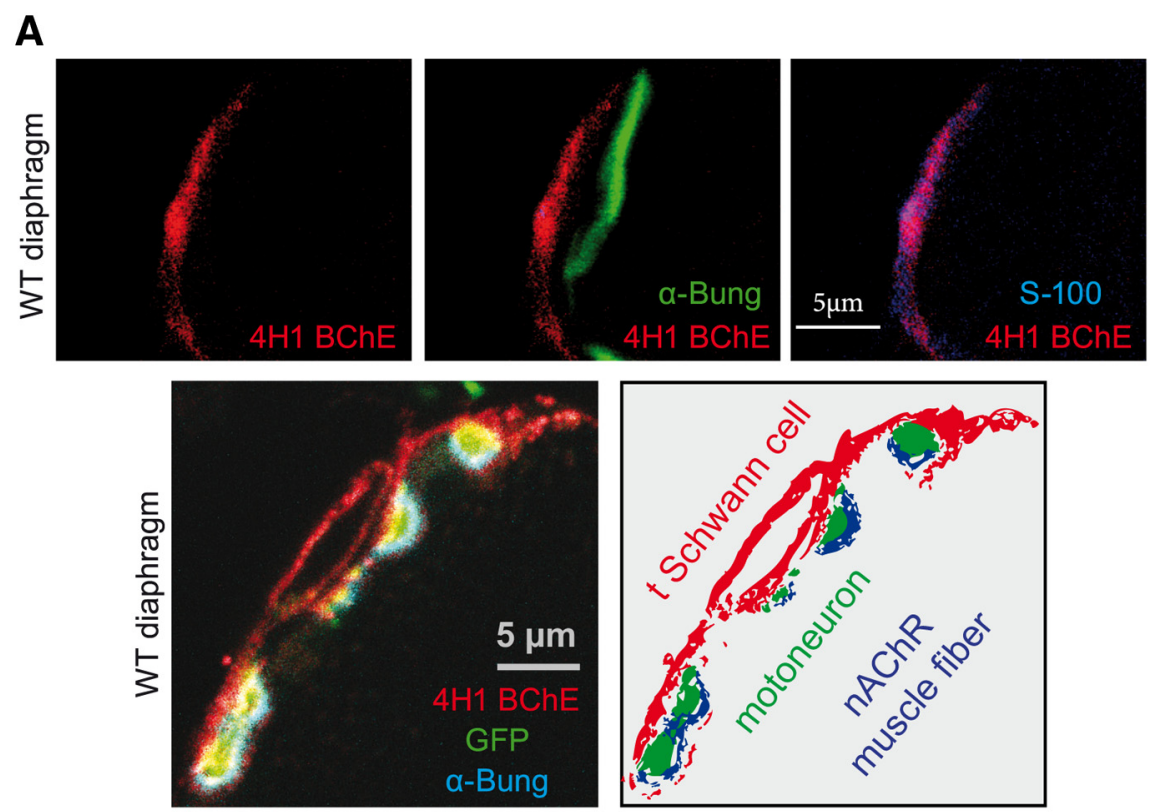

B
WT diaphragm

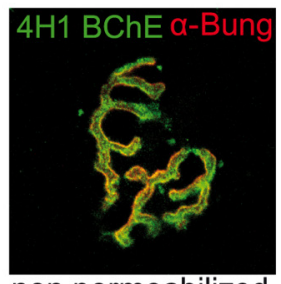

non permeabilized

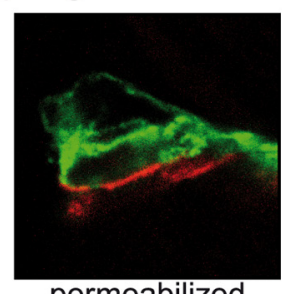

permeabilized
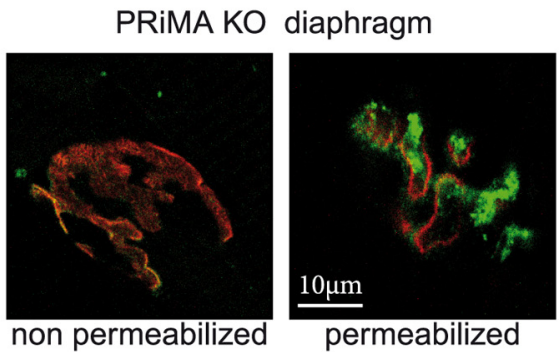

permeabilized
C

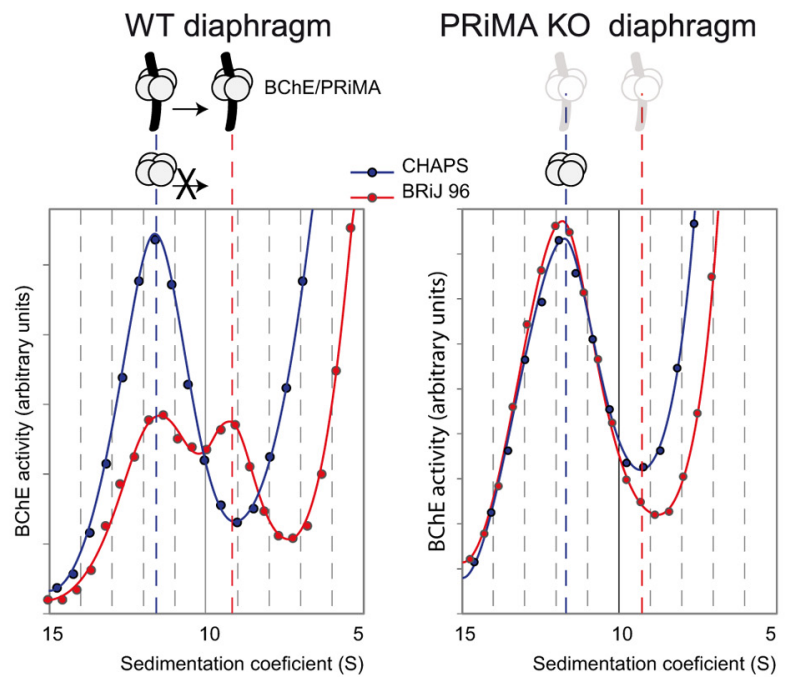

Figure 1. $B C h E$ is localized at the TSC with PRiMA. A, Top, BChE was labeled with biotinylated $4 \mathrm{H} 1$ (red), the muscle $n A C h R$ localized on the top of the fold at the surface were labeled with $\alpha$-bungarotoxin (green), and S100 a specific marker of the TSCS were labeled with specific antibodies (blue). The overlay of $\mathrm{BChE} / \alpha$-bungarotoxin labeling (middle) and of $\mathrm{BChE} / \mathrm{S} 100$ labeling (right) shows that BChE is mainly localized at the TSC. Bottom, Immunolocalization with biotinylated $4 \mathrm{H} 1$ (red) in a mouse strain in which the motoneuron are labeled by membrane tethered GFP (green). The muscle nAChR are labeled with $\alpha$-bungarotoxin (blue). The drawing illustrates the localization of $\mathrm{BChE}$ on the surface of the TSC. $B$, Labeling of $B C h E$ with biotinylated $4 \mathrm{H} 1$ (green) and of muscle nAChR with $\alpha$-bungarotoxin (red) in muscle diaphragm of WT and PRiMA KO mice. Nonpermeabilized indicates that the muscle was incubated in toto without permeabilization before the application of antibodies and toxin. Note the absence of BChElabeling in PRiMA KO mice. Permeabilized indicates that frozen sections of muscle were incubated with antibodies and toxins. Note the presence of BChE in WT and PRiMA KO mice. The labeling in PRiMA KO mice appears more spotted than in WT mice. the distribution of BChE at the surface of the TSC in WT and its retention inside the cells in PRiMA KO mice reveal that $\mathrm{BChE}$ is mainly anchored by PRiMA at the surface of the TSC.

We then analyzed the molecular forms of BChE extracted and solubilized from the whole diaphragm. BChE is found mainly as monomers (data not shown), but, as shown in Figure 1C, BChE is also found in tetramers. A peak of BChE activity around $11.5 \mathrm{~S}$ was observed when the extracts were separated using CHAPS as the detergent. The separation of the tetramers with Brij 97 instead of CHAPS revealed the presence of two types of $\mathrm{BChE}$ tetramers: a soluble BChE tetramer that did not shift in presence of BRIJ97 and an amphiphilic tetramer that was shifted with Brij 97. The soluble BChE tetramer is the abundant form of BChE found in the serum and its presence is presumably accounted by the residual serum in the muscle. The amphiphilic BChE tetramer is absent in PRiMA KO mice, demonstrating that the amphiphilic BChE tetramer contains PRiMA.

BChE inhibition decreases the quantal content of EPP when AChE is active We next addressed the question of the function of BChE anchored at the surface of the TSC. We have previously shown that, when AChE is absent or inhibited, inhibition of $\mathrm{BChE}$ reduces the probability of ACh release (Minic et al., 2003). If a similar modulation exists when AChE is active, one expects to observe a reduction the EPP quantal content (QC) after inhibition of BChE. The EPP QC at low frequency of nerve stimulation varies significantly between the NMJs of the diaphragm muscle, but little for a given NMJ during experiments performed ex vivo. Therefore, we analyzed the effect of BChE inhibition on the EPP QC at the level of a single NMJ (Fig. 3A). We found that the EPP QC was reduced by $18 \%$ after $30 \mathrm{~min}$ application of $50 \mu \mathrm{M}$ iso-OMPA, a

\section{$\leftarrow$}

Altogether, these images show that $\mathrm{BChE}$ is mainly anchored by PRiMA at the surface of the TSC at the NMJ. C, Two BChE tetramers are found in the diaphragm. Enzymes were solubilized and loaded in sucrose gradients containing CHAPS or Brij as the detergent. After centrifugation, BChE activity was determined in all of the fractions. The figure presents a part of the gradient around the peaks of $\mathrm{BChE}$ activity that correspond to the tetramer. In the CHAPS gradient, the peak at $11.5 \mathrm{~S}$ corresponds to the tetramers. Amphiphilic tetramer (interaction with detergent) shifts in the presence of Brij and is absent in PRiMA KO mice, demonstrating that some of the tetramers of BChE are anchored by PRiMA. 
specific, irreversible BChE inhibitor. To validate the selectivity of iso-OMPA toward BChE in our experimental conditions, we measured the EPP QC in BChE $\mathrm{KO}$ mice and found that it did not change significantly after application of isoOMPA (Fig. 3B); then, we compared the mean QC in WT and BChE KO mice and found a reduction of $30 \%$ of the mean QC in BChE $\mathrm{KO}$ mice compared with WT mice (Fig. 3C). Therefore, the EPP QC is reduced both in $\mathrm{BChE} \mathrm{KO}$ mice and after the specific pharmacological inhibition of BChE, likely through the action of residual ACh on AChRs.

Because BChE is localized on TSCs, we wanted to find out whether TSCs contribute to the reduction of $\mathrm{ACh}$ release after BChE inhibition or if they simply act as a scaffold localizing BChE close to, but outside of, the synaptic cleft. To address this question, we lowered specifically the metabolism of the TSC with fluorocitric acid, a Krebs' cycle blocker that affects mainly the glial cells (Bonansco et al., 2011). Incubation in fluorocitric acid (0.2 $\mathrm{mm})$ during $1 \mathrm{~h}$ did not alter significantly the EPP QC (92 $\pm 5 \%, n=5)$, but when fluorocitric acid was washed out and BChE was inhibited by iso-OMPA (50 $\mu \mathrm{M}, 30$ min), the EPP QC was not significantly reduced (95 $\pm 6 \%, n=5$ ). This result suggests that TSCs may participate actively in the reduction of EPP QC after BChE inhibition.

\section{Blockade of $\alpha 7$ receptors prevents the depression of $\mathrm{ACh}$ release after BChE inhibition}

The effects of BChE inhibition suggest that the excess of $\mathrm{ACh}$ resulting from this inhibition depresses ACh release. To identify the ACh receptors mediating this depression, we estimated the EPP QC after blockade of muscarinic receptors ( $1 \mu \mathrm{M}$ atropine) and in the absence of nicotinic $\beta 2, \beta 4$, or $\alpha 7$ receptors (in $\beta 2 \mathrm{KO}, \beta 4 \mathrm{KO}$, or $\alpha 7 \mathrm{KO}$ mice, respectively). The incubation of the ex vivo nerve-muscle preparations from WT mice with atropine did not prevent the reduction of the EPP QC observed after the specific BChE inhibition by iso-OMPA (Fig. 3C). EPP QC was also decreased after iso-OMPA incubation of ex vivo unitary nerve-muscle preparations from $\beta 2 \mathrm{nAChR} \mathrm{KO}$ and $\beta 4 \mathrm{nAChR}$ $\mathrm{KO}$ mice, as in the WT mice (Fig. $3 C$ ). In stark contrast, the incubation with isoOMPA of ex vivo diaphragms obtained from $\alpha 7 \mathrm{nAChR}$ KO mice did not change the EPP QC (Fig. 3C). To further explore the implication of $\alpha 7 \mathrm{nAChR}$, we incubated the WT muscle preparation with 10
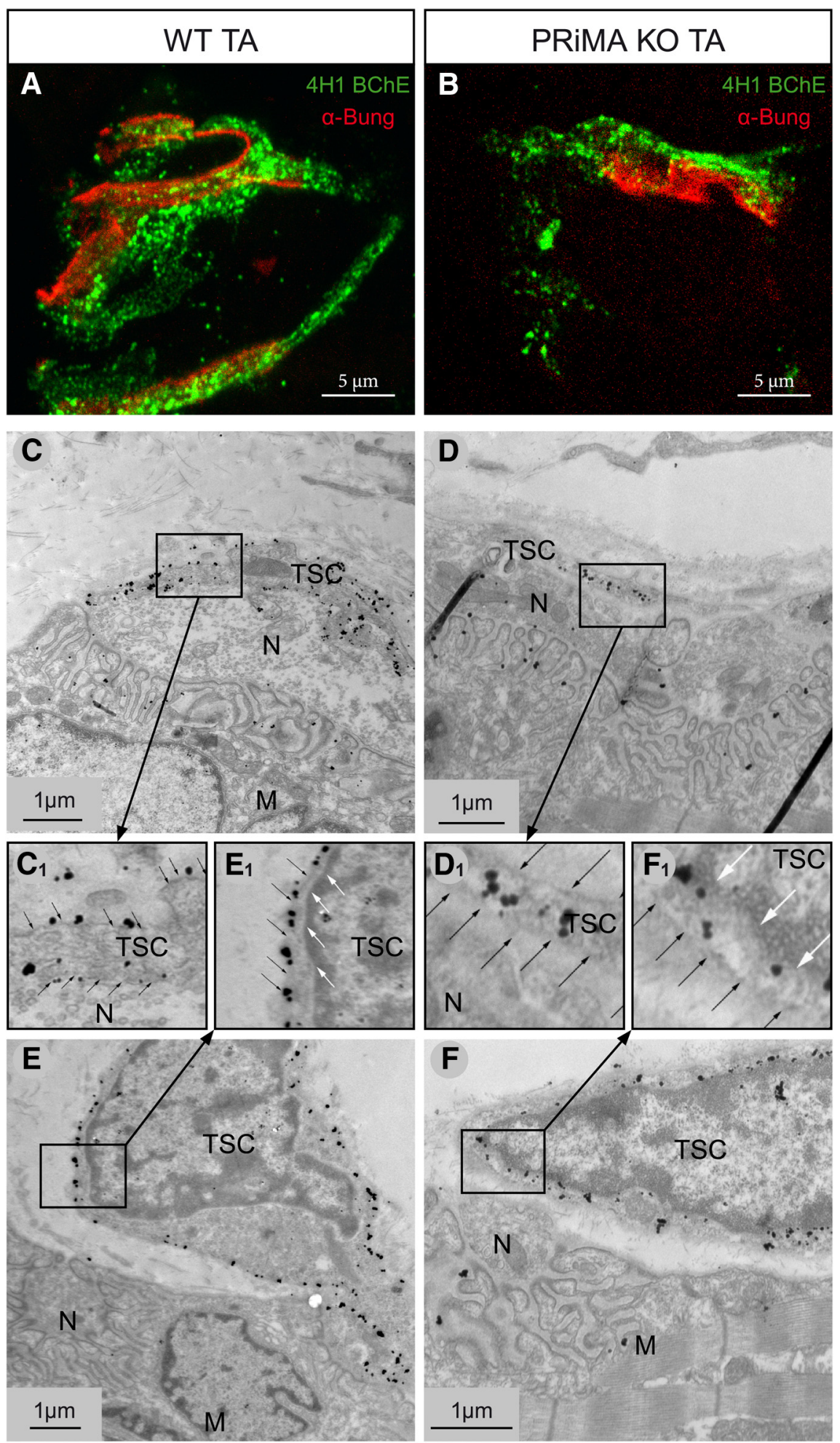

Figure 2. BChE is anchored by PRiMA at the surface of the TSC. $A, B$, At light microscopy, labeling of BChE with biotinylated $4 \mathrm{H} 1$ (green) and of muscle nAChR with $\alpha$-bungarotoxin (red) in tibialis muscle in WT $(\boldsymbol{A})$ and PRiMA KO (B) tibialis anterior muscle. Note the apparent weaker signal in PRiMA KO mice versus WT. $C-F$, At the EM level, labeling of BChE with biotinylated $4 \mathrm{H} 1$ was revealed by $1.4 \mathrm{~nm}$ gold particle enhanced with silver $(\boldsymbol{C}, \boldsymbol{E})$. At NMJ of WT mice, the immunoparticles are localized along the plasma membrane. $\boldsymbol{C}$, Membrane extensions close to the nerve terminal at the NMJ are labeled at the surface. $\boldsymbol{E}$, The plasma membrane of cell body close to the NMJ is also labeled. $\mathbf{C 1}, \boldsymbol{E 1}$, Enlargement of the inserts in the $\boldsymbol{C}$ and $\boldsymbol{E}$. Black and white arrows point to the plasma membrane and the membrane of the nucleus, respectively. $\boldsymbol{D}, \boldsymbol{F}$, At the NMJ of PRiMA KO mice, immunoparticles are localized only in the cytoplasm, not along the plasma membrane. $\boldsymbol{F}$, The plasma membrane of cell body close to the NMJ is not labeled; all of the immunoparticles are inside the cells. D1, $\boldsymbol{F 1}$, Enlargements of the inserts illustrating the intracellular localization of $\mathrm{BChE}$ in PRiMA KO mice close to the nucleus (white arrows) and the absence at the surface (black arrow). N, Nerve terminal; M, muscle fiber. 


\section{A Experimental scheme}

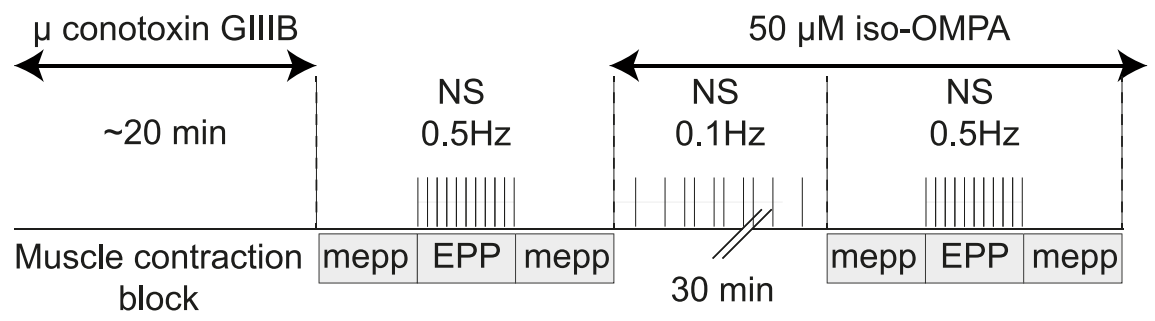

Recording in the same muscle fiber

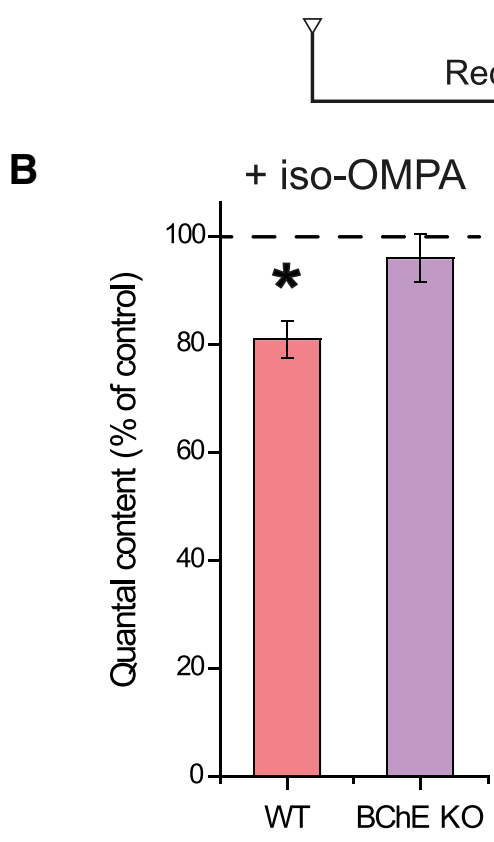

B

D

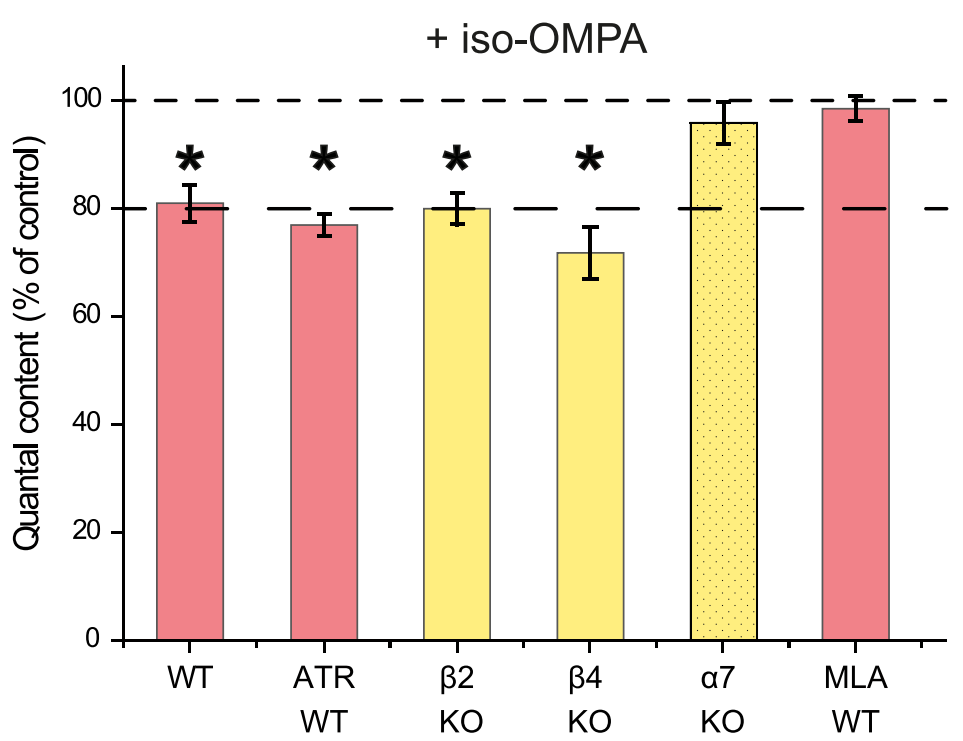

Figure 3. $B C h E$ inhibition depresses $A C h$ release at the NMJ. A, Experimental protocol. The muscle contraction was blocked by inhibition of the muscle voltage-gated sodium channels with $\mu$-conotoxin GIIIB. A sharp electrode was inserted close to a NMJ to record focal $\mathrm{mEPPS}$ and EPPs. A first file was obtained for the mEPPs (no nerve stimulation), then a second for the EPP ( $0.5 \mathrm{~Hz}$ nerve stimulations), and then a third for the mEPPs (no stimulation). Iso-0MPA (50 $\mu \mathrm{m}$ ) was added to the Ringer's buffer and the muscle was stimulated indirectly at $0.1 \mathrm{~Hz}$ during the incubation. The electrode was maintained in place. All of the records were obtained in 30 - $40 \mathrm{~min}$. The QC was obtained by dividing the mean amplitude of the EPPs by the mean amplitude of the mEPPs recorded before and after the EPPs if the resting membrane potential (RMP) did not change $>1 \mathrm{mV}$ during mEPP and EPP recording. $\boldsymbol{B}$, Quantification of the $Q C$ in the same muscle fiber after inhibition of $B C h E$ with iso-OMPA. The percentage of decrease of the $Q C$ in
nM MLA, which is a specific inhibitor of $\alpha 7 \mathrm{nAChR}$, and followed the EPP QC before and after iso-OMPA addition to the bath containing the ex vivo nerve-muscle preparations (Fig. 3C), QC was not changed by iso-OMPA. It is worthwhile to emphasize that MLA did not affect the EPP QC in $\alpha 7 \mathrm{KO}$ mice.

From these experiments, it can be concluded that the decrease of EPP QC induced by $\mathrm{BChE}$ inhibition is mediated by $\alpha 7 \mathrm{nAChR}$.

$\alpha 7 \mathrm{nAChRs}$ are localized and functional at the TSC of the NMJ

To analyze how activation of $\alpha 7 \mathrm{nAChRs}$ may depress the release of $\mathrm{ACh}$, we attempted to localize them at the NMJ using polyclonal antibodies directed against mouse $\alpha 7$ nAChR (Kalashnyk et al., 2012). As shown in Figure $4 A$, we obtained a reproducible weak signal at the NMJ identified by $\alpha$-bungarotoxin labeling. $\alpha$-Bungarotoxin is an $\alpha$-neurotoxin known to bind irreversibly and competitively to the nAChRs found at the NMJ and to $\alpha 7 \mathrm{nAChRs}$ in the brain. The specificity of $\alpha 7 \mathrm{nAChR}$ labeling observed with the polyclonal antibodies used is substantiated by the absence of any detectable immunolabeling in $\alpha 7 \mathrm{KO}$ mice with the same polyclonal antibodies. The weak $\alpha 7$ nAChR immunolabeling observed did not overlap with the strong labeling obtained with fluorescent $\alpha$-bungarotoxin. At the EM level, we also found a dense deposit of gold particles along the postsynaptic membrane labeled with $\alpha$-bungarotoxin. However, we did not find gold particles along the plasma membranes of the TSC or the nerve terminal. Moreover, immunoparticles that were not associated with the muscle membranes appeared equally distributed in WT and $\alpha 7$ KO muscle preparation. Altogether, these observations failed to reveal $\alpha 7 \mathrm{nAChR}$ by using labeled $\alpha$-bungarotoxin, presumably because the density of $\alpha 7 \mathrm{nAChR}$ on the TSC is much lower than that of the muscle postsynaptic receptors. A low density of $\alpha 7 \mathrm{nAChR}$ was previously observed

\section{$\leftarrow$}

WT mice is higher than in BChE KO mice $\left(n=5,{ }^{*} p<0.05\right.$, paired Student's t test). $C$, The mean QC in the NMJs of WT mice is higher than in BChE KO mice $\left(n=20,{ }^{*} p<0.05\right.$, and $n=5$, ${ }^{*} p<0.05$, respectively, unpaired Student's $t$ test). D, Quantification of the $Q C$ in the same muscle fiber after inhibition of BChE with iso-OMPA when AChRs are absent or blocked. The graph presents the quantification of the $Q C$ in the same muscle fiber after iso-0MPA. All of the muscarinic receptors were blocked with $1 \mu \mathrm{m}$ atropine $\left(n=5,{ }^{*} p<0.05\right.$, paired Student's $t$ test). 
in brain astrocytes (Vélez-Fort et al., 2009). To further analyze the distribution of $\alpha 7 \mathrm{nAChR}$, we looked for colocalization labeling with $\mathrm{S} 100$, a specific marker of TSCs. We found a colabeling of $\alpha 7 \mathrm{nAChR}$ with $\mathrm{S} 100$, but not with $\alpha$-bungarotoxin (Fig. 3B). These observations suggest that the $\alpha 7 \mathrm{nAChRs}$ detectable with the polyclonal antibodies are mainly on the TSCs.

TSCs are close to the nerve terminal and sensitive to the synaptic transmission (Auld and Robitaille, 2003). The hallmarks of TSC sensitivity to the synaptic activity are calcium waves recorded specifically in the TSCs after long bursts of nerve stimulations (Todd et al., 2010). We generated calcium waves at the TSC by $120 \mathrm{~s}$ nerve stimulations $(20 \mathrm{~Hz})$ in presence of $\mu$-conotoxin GIIIB (a specific muscle voltage-gated sodium channel blocker used to prevent muscle contraction). After 30 min of recovery, the calcium waves were again generated by $120 \mathrm{~s}$ nerve stimulations $(20 \mathrm{~Hz})$. To evaluate whether $\alpha 7 \mathrm{nAChRs}$ mediate this signaling, the muscle preparation was incubated during the recovery period (30 min) with $10 \mathrm{~nm}$ MLA ( $n=5$ experiments). We found that the second calcium waves were totally abolished after MLA, but not in control (Fig. 4C). This result supports that $\alpha 7 \mathrm{nAChRs}$ are functional at the TSC, where they are activated by the spillover of ACh. This can actually occur for prolonged stimulations, even when both $\mathrm{AChE}$ and $\mathrm{BChE}$ are active, but is likely to be much larger in extreme physiological circumstances and/or medical or pathological conditions.

\section{$\mathrm{AChE}$ and $\mathrm{BChE}$ coinhibition decreases the mean amplitude of EPP \\ The previous experiments revealed that the selective inhibition of $\mathrm{BChE}$ anchored at the surface of TSCs reduces ACh re- lease. This means that, in the presence of AChE, some ACh must escape the cleav-} age by AChE clustered in the synaptic cleft to reach BChE. This spillover is likely to be moderate, which might explain the modest inhibition of the synaptic transmission observed after BChE specific inhibition at low frequency of nerve stimulation. The inhibition of both AChE and BChE is expected to increase the spillover of ACh and should increase the depression of the EPP QC. Unfortunately, after AChE inhibition, the direct estimation of the QC as the summation of the individual quanta (mEPP) is not possible. In normal conditions, EPP is the simple sum of individual mEPPs. After AChE inhibition, the surfaces of the postsynaptic area ultimately reached by individual quanta overlap, so the number of quanta released cannot be calculated as the quotient of EPP by the mEPP (Hartzell et al., 1975). We thus calculated the mean value of EPP amplitude recorded in the same area of the diaphragm. The amplitude of EPPs is the key param-
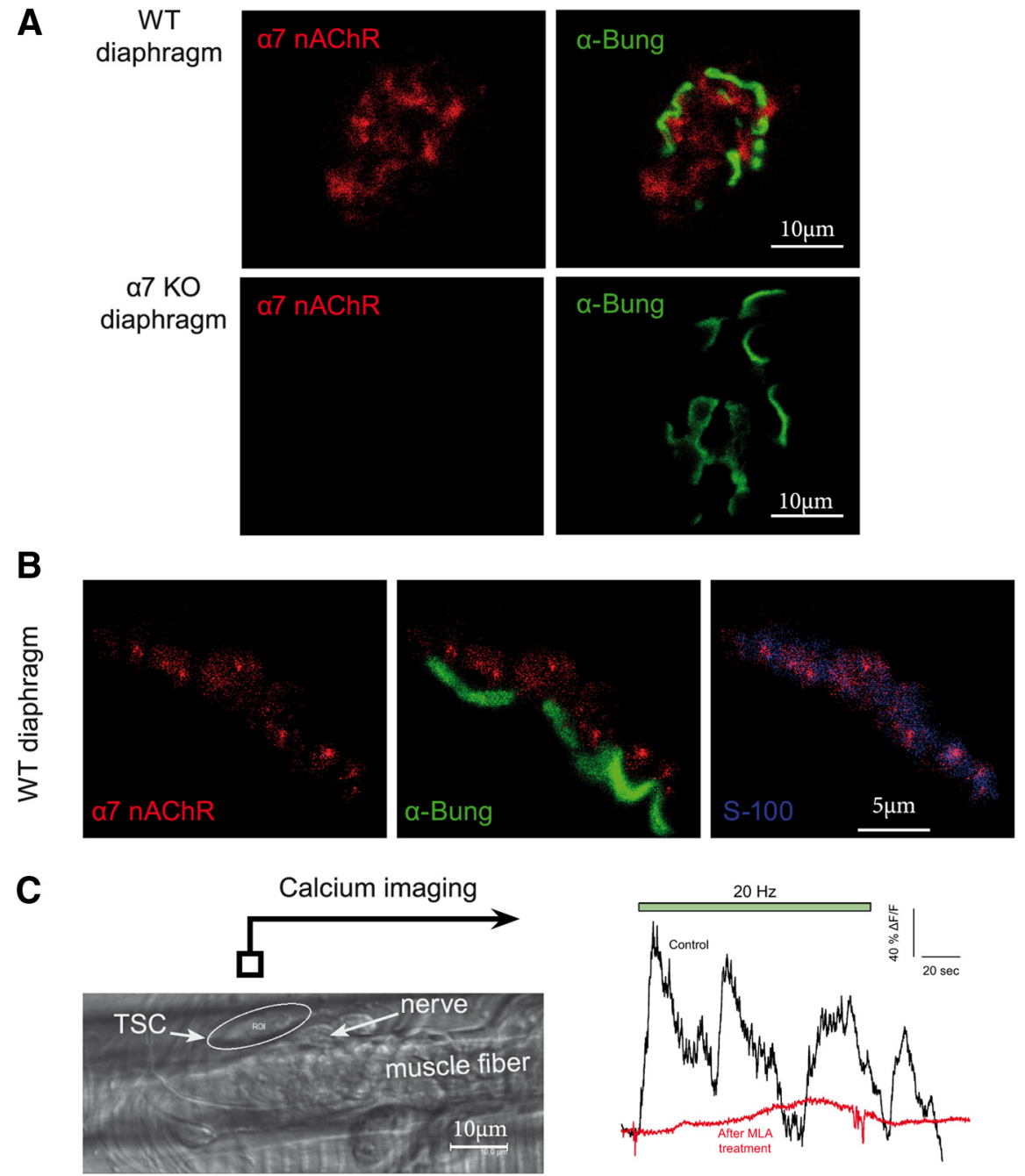

mouse LAL muscle

Figure 4. $\quad \alpha 7$ nicotinic receptors are localized at the NMJ on the TSC. $\boldsymbol{A}$, Immunolocalization of $\alpha 7 \mathrm{nAChR}$ at the NMJ. WT or $\alpha 7$ KO diaphragm muscles were incubated with a polyclonal antibody directed against $\alpha 7 \mathrm{nAChR}$ (red). The NMJs were identified with labeled in red, the muscle $n A C h R s$ are labeled with $\alpha$-bungarotoxin (green), and S100 is labeled with a specific antibody (blue). The overlay of $\alpha 7 \mathrm{nAChR} / \alpha$-bungarotoxin labeling (middle) and of $\alpha 7 \mathrm{nAChR} / \mathrm{S} 100$ labeling (right) shows that $\alpha 7 \mathrm{nAChR}$ is mainly wave had been triggered in the TSC by a first long burst of nerve stimulations, the preparation was left to rest for 30 min with or

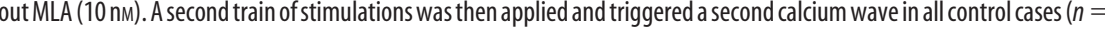
ISC as a region of interest (ROI). Right, Mean Fintensity from ROI represented on transmitted channel image before and after MLA treatment. Green panel is the time of nerve stimulations $(20 \mathrm{~Hz}, 120 \mathrm{~s})$.

eter for neuromuscular synaptic transmission. The muscle contraction occurs only if the EPPs pass the threshold of AP generation. To record the full EPP, the APs were blocked with $\mu$-conotoxin GIIIB. The resting membrane potential was constant. The mean EPP amplitude was $31.5 \pm 0.95 \mathrm{mV}$ in control diaphragm and, after $\mathrm{AChE}$ and $\mathrm{BChE}$ inhibition ( $3 \mu \mathrm{M}$ neostigmine, $20 \mathrm{~min}$ ), it decreased to $14.2 \pm 0.75 \mathrm{mV}$ (Fig. $5 D$ ). It is important to note that the amplitude of $\mathrm{mEPCs}$ recorded in the interstimuli intervals after ChE inhibition by neostigmine was higher than in the untreated intact preparation (Fig. 5B). Therefore, after the inhibition of AChE and BChE, the reduction of the number of quanta released was likely larger than the reduction of the EPP amplitude.

To test the involvement of $\alpha 7 \mathrm{nAChR}$, we used both MLA, a specific blocker of $\alpha 7 \mathrm{nAChR}$, and $\alpha 7 \mathrm{KO}$ mice. After $30 \mathrm{~min}$ incubation of the diaphragms of WT mice with MLA (10 nM), the 


\section{A Experimental protocol}

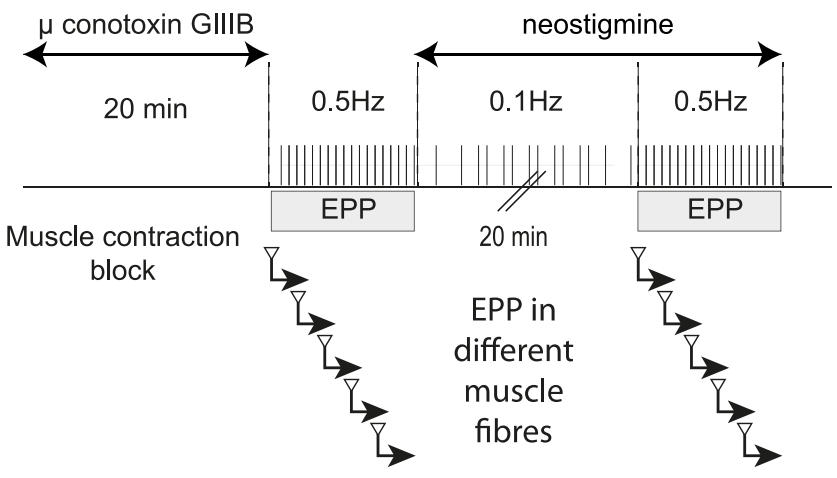

\section{B Examples of EPPs}

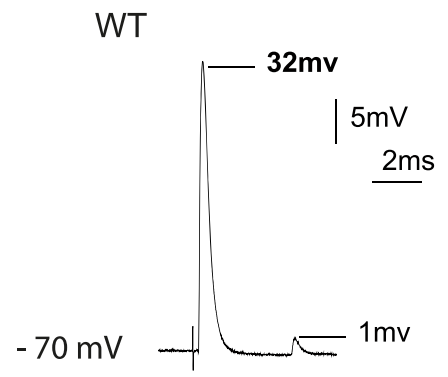

\section{Threshold of AP}

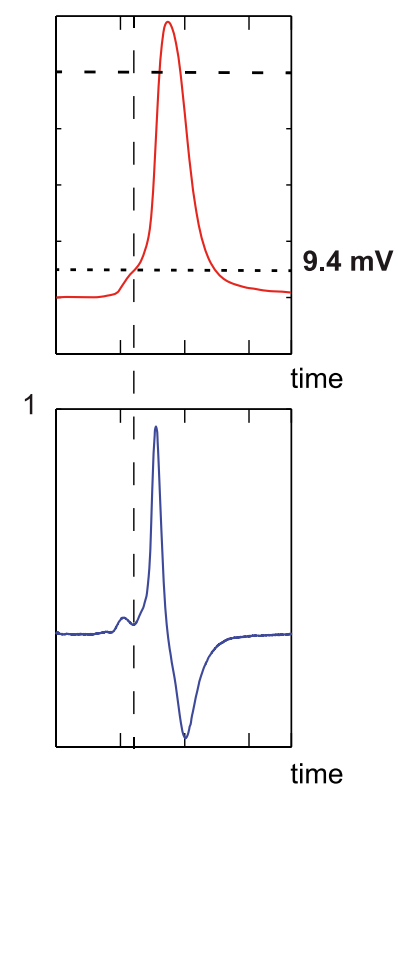

\section{Quantification of EPP amplitudes}

WT + neostigmine

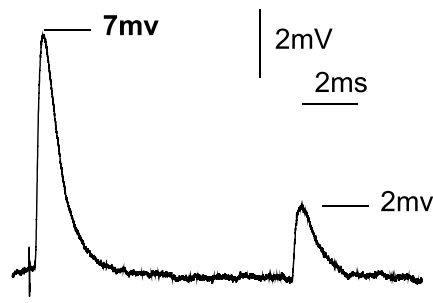

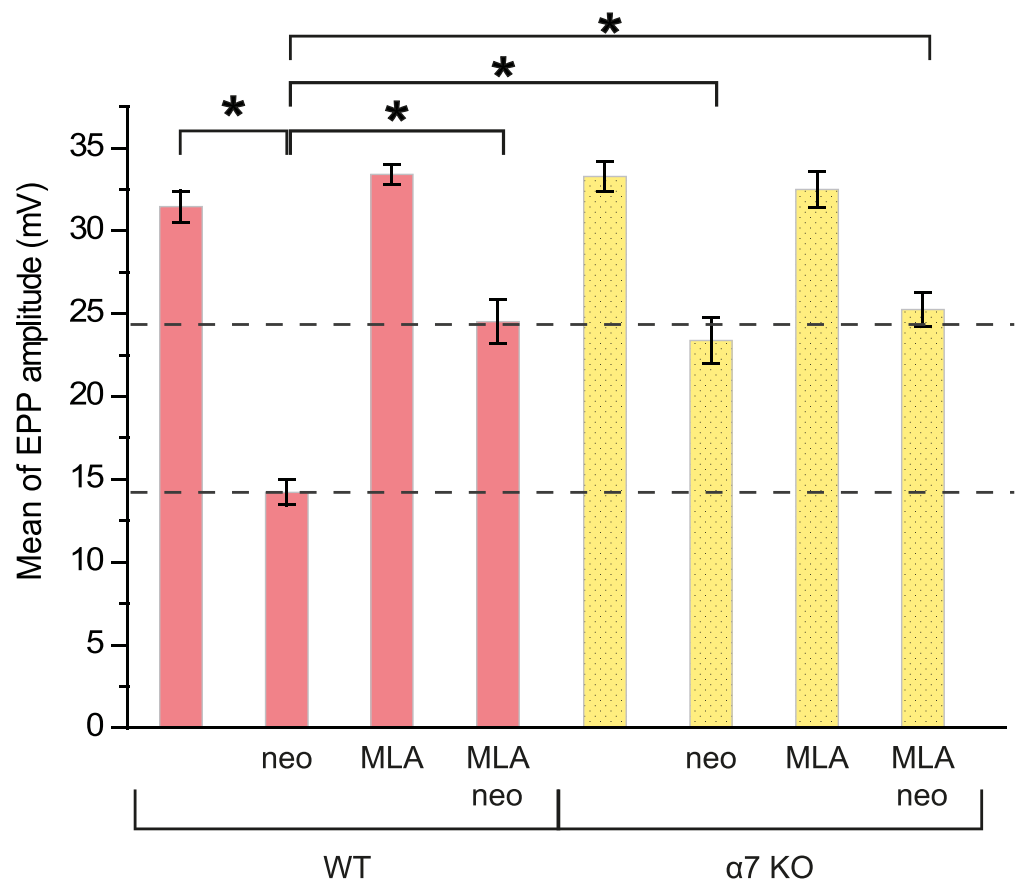

Figure 5. The amplitudes of the EPP are rescued partially by the block of $\alpha 7 \mathrm{nAChR}$ when both cholinesterases were inhibited. $\boldsymbol{A}$, Experimental protocol. The muscle contraction in diaphragm was blocked by $\mu$-conotoxin GIIIB. Fifty EPPs were recorded from each muscle fiber. Only data from the fibers in which the resting membrane potential was $>70 \mathrm{mV}$ at the end of the recording have been used. Mean amplitude of EPPs was obtained from 20 -30 fibers recorded in control conditions and after application of the drugs (neostigmine, MLA). $\boldsymbol{B}$, Examples of EPPs recorded before and after cholinesterase inhibition with $3 \mu \mathrm{m}$ neostigmine. Note the difference of scale between the two conditions. In each of the selected traces, one EPP and one mEPP are visible. $\boldsymbol{C}$, Evaluation of the threshold of nerve-evoked muscle fiber APs. The phrenic nerve was stimulated once for recording an AP in each muscle fiber. The resting membrane potential was $-70 \mathrm{to} 75 \mathrm{mV}$. Records of APs were differentiated (lower profile, $\mathrm{dV} / \mathrm{dt}$ ) and the time point on the rising phase of the nerve-evoked AP when the rate of change of voltage with time was closest to zero was determined. The threshold was defined as the voltage at this time. $D$, Mean amplitude of EPPs recorded in the phrenic-diaphragm preparations of WT mice and $\alpha 7 \mathrm{nAChRKO}$ mice in control conditions and after application of the drugs (neostigmine $3 \mu \mathrm{m}, \mathrm{MLA} 10 \mathrm{~nm} ; n=20-30,{ }^{*} p<0.05$, unpaired Student's ttest). 
mean EPP was unchanged at $33.4 \pm 0.6 \mathrm{mV}$. Then, after $20 \mathrm{~min}$ incubation with neostigmine $(3 \mu \mathrm{M})$, the mean EPP decreased only to a value of $24.5 \pm 1.3 \mathrm{mV}$. The mean EPP amplitude was $33.3 \pm 0.9 \mathrm{mV}$ in the diaphragms of $\alpha 7 \mathrm{KO}$ mice and $23.4 \pm 1.4$ $\mathrm{mV}$ after $20 \mathrm{~min}$ of incubation with neostigmine. We also controlled the specificity of MLA by treating muscles of $\alpha 7 \mathrm{KO}$ mice. The mean EPP amplitude in $\alpha 7 \mathrm{KO}$ mice treated by MLA (10 nM) was $32.5 \pm 1.1 \mathrm{mV}$ before and $25.2 \pm 1.0 \mathrm{mV}$ after neostigmine. These results unambiguously reveal that the activation of $\alpha 7$ nAChR significantly reduces the amplitude of EPP after inhibition of cholinesterase by neostigmine.

The amplitude of EPP after inhibition of AChE and BChE was found to be close to the threshold of AP generation evaluated in extensor digitorum longus and soleus muscles of rat ( $13 \mathrm{mV}$ and 14 $\mathrm{mV}$, respectively; Wood and Slater, 1995). To perform a direct comparison with the mouse diaphragm, we estimated the threshold of AP generation in mouse diaphragm when both cholinesterases were inhibited by $3 \mu \mathrm{M}$ neostigmine (Fig. $5 C$ ). The average level of threshold of AP generation was $13 \pm 3 \mathrm{mV}(n=20)$, a value close to the mean EPP amplitude $(14.2 \pm 0.75 \mathrm{mV})$ obtained after complete inhibition of all cholinesterases with neostigmine. In contrast, the amplitudes of the EPP appear higher after inhibition of cholinesterases when $\alpha 7 \mathrm{nAChR}$ are absent or inactivated.

\section{AChE and BChE coinhibition and muscle contraction}

The decrease of EPP amplitude close or below to the threshold of AP after AChE and BChE inhibition should be translated at the physiological level into a reduction of the muscle contraction triggered by the nerve. The anesthetists routinely assess via neuromuscular monitors the decrease of the EPP amplitude during muscle relaxation. They follow the modification of the muscle contractions triggered by the nerve stimulations. A sensitive method to monitor the neuromuscular blockade is used. The TOF stimulation method consisted of recording the four muscle contractions elicited by four nerve stimulations at $2 \mathrm{~Hz}$ (Ali et al., 1975; Srivastava and Hunter, 2009; Plaud et al., 2010). Next, the ratio of the fourth over the first response, known as the TOF ration (TOFR), which reflects the degree of neuromuscular blockade during onset and recovery after nondepolarizing muscle relaxant administration, can be calculated. When this pattern of stimulation was applied to the phrenic nerve diaphragm preparation ex vivo, the amplitudes of the four twitches were identical during hours if TOFs were repeated every $30 \mathrm{~s}$ (Fig. 6A). We then examined the effects of neostigmine on the first twitch (T1) and on T2-T4. After $20 \mathrm{~min}$ of incubation with $3 \mu \mathrm{M}$ neostigmine, the mean amplitude of T1 decreased to $60 \%$ of the initial amplitude in WT muscle (Fig. $6 B, C$ ). A concentration of $0.1 \mu \mathrm{M}$ atropine (to block all of the muscarinic receptors) did not change the reduction of the T1. In contrast, after blockade of $\alpha 7$ nAChR (MLA treatment, $10 \mathrm{nM}$ ) or in $\alpha 7 \mathrm{KO}$ mice, the mean amplitudes of $\mathrm{T} 1$ did not decrease in neostigmine (Fig. 6B,C). Therefore, as expected, the partial recovery of the amplitude of the EPP after $\alpha 7$ $\mathrm{nAChR}$ block following $\mathrm{AChE}$ and $\mathrm{BChE}$ inhibition described in the preceding section is translated in the recovery of T1 amplitude during supramaximal stimulation. These changes required $20 \mathrm{~min}$ to be effective and were maintained over time.

The analysis of T2-T4 revealed an additional process. When cholinesterases were inhibited in WT, the amplitudes of T4 were smaller than T1 (TOFR 0.7). These events occur during the range of few hundred milliseconds to seconds after $\mathrm{T} 1$ and are cumulative with T2 and T3. These events are reversible: after $28 \mathrm{~s}$, the amplitude of T1 is returned to the value of T1 of the TOFn-1. A similar ratio was observed after inhibition of muscarinic recep- tors by atropine. Unexpectedly, the TOFR was also $\sim 0.6-0.7$ when $\alpha 7 \mathrm{nAChR}$ was not functional, even when T1 mean amplitudes were maintained. To ensure that the decrease of the contraction did not result from the failure of the muscle function, but rather from a decrease of the synaptic transmission, we stimulated the muscles directly. Synaptic transmission was blocked with D-tubocurarine (a nAChR blocker). In these conditions, the four responses after TOF stimulation were identical to the control responses (Fig. 6B,C). Therefore, the reduction of the contraction was due to an alteration in synaptic transmission. The interpretation of this second process needs more investigation and is outside of the scope of this study.

\section{AChE specific versus $\mathrm{AChE} / \mathrm{BChE}$ nonspecific inhibitors in the treatment of MG}

MG is a chronic autoimmune neuromuscular disorder that is characterized by the weakness of voluntary muscle groups. The fluctuating weakness becomes apparent with physical activity and is reversed at rest. Eighty percent of MGs are caused by antibodies directed against muscle nAChRs. These antibodies reduce the number of functional nAChRs at NMJ (Vincent, 2010) and thus the amplitude of the EPP. Pyridostigmine and other cholinesterase inhibitors are commonly used as treatment for MG. When the amplitude of EPPs does not reach the depolarization threshold needed to trigger AP, and thus the contraction of the muscle, AChE inhibition extends the action of ACh and increases the amplitude of EPP. In contrast to this positive action, inhibition of $\mathrm{BChE}$ in addition to AChE might have the opposite effect by depressing $\mathrm{ACh}$ release and thus reducing the muscle contraction.

To test this hypothesis, we generated an animal model of MG in which rats were immunized with a synthetic peptide (Baggi et al., 2003). After immunization, 50\% of all animals developed a moderate MG. The evolution of MG was followed by the reduction of the amplitude of the integral muscle APs triggered by the sciatic nerve stimulation by train of 200 pulses applied at $40 \mathrm{~Hz}$. In healthy rats, the amplitude of 200th AP (AP200) was $95 \pm 1 \%$ of the first one (AP1; Fig. $7 B, C)$. In the affected animals, AP200 was reduced to $81 \pm 1 \%$ (Fig. $7 B, C$ ). Intraperitoneal injection of $5 \mu \mathrm{g} / \mathrm{kg}$ ambenonium (a selective AChE inhibitor that does not cross the blood-brain barrier) maintained the AP200 to control level after $30 \mathrm{~min}$ and for several hours (AP200 was $95 \pm 1 \%$ of AP1). In contrast, intraperitonial injection of $0.2 \mathrm{mg} / \mathrm{kg}$ bambuterol (a selective inhibitor of $\mathrm{BChE}$ ) after ambenonium reduced AP200 to a value of $90 \pm 1 \%$ (Fig. $7 B, C$ ).

These in vivo experiments suggest that the differential actions of $\mathrm{AChE}$ and $\mathrm{BChE}$ can be used to improve the treatment of MG.

\section{Discussion}

We have identified a negative feedback loop controlling neurotransmitter release at the mammalian NMJ (Fig. 8). When ACh spillover is increased, $\alpha 7 \mathrm{nAChR}$ activation depresses ACh release. $\alpha 7 \mathrm{nAChRs}$ work as sensors of ACh outside of the synaptic cleft. Their activation is controlled by BChE anchored by PRiMA on the surface of TSCs at mouse NMJs. The presence of an ACh sensor that reduces release may explain some effects of AChE inhibitors that are commonly used to improve the synaptic transmission at the NMJ in patients affected with MG or to reverse residual blockade at the end of an anesthesia procedure requiring the use of a muscle relaxant. The differential functions of AChE in the synaptic cleft and BChE on the TSC have to be taken into account and suggest that specific AChE inhibitors should be used to ensure the best management in pathological conditions. 


\section{A Experimental protocol}

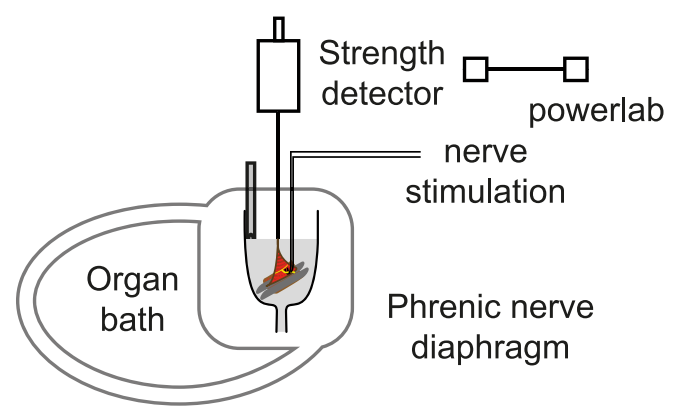

amplitude of muscle twitch

\section{B Examples TOF recorded ex-vivo}

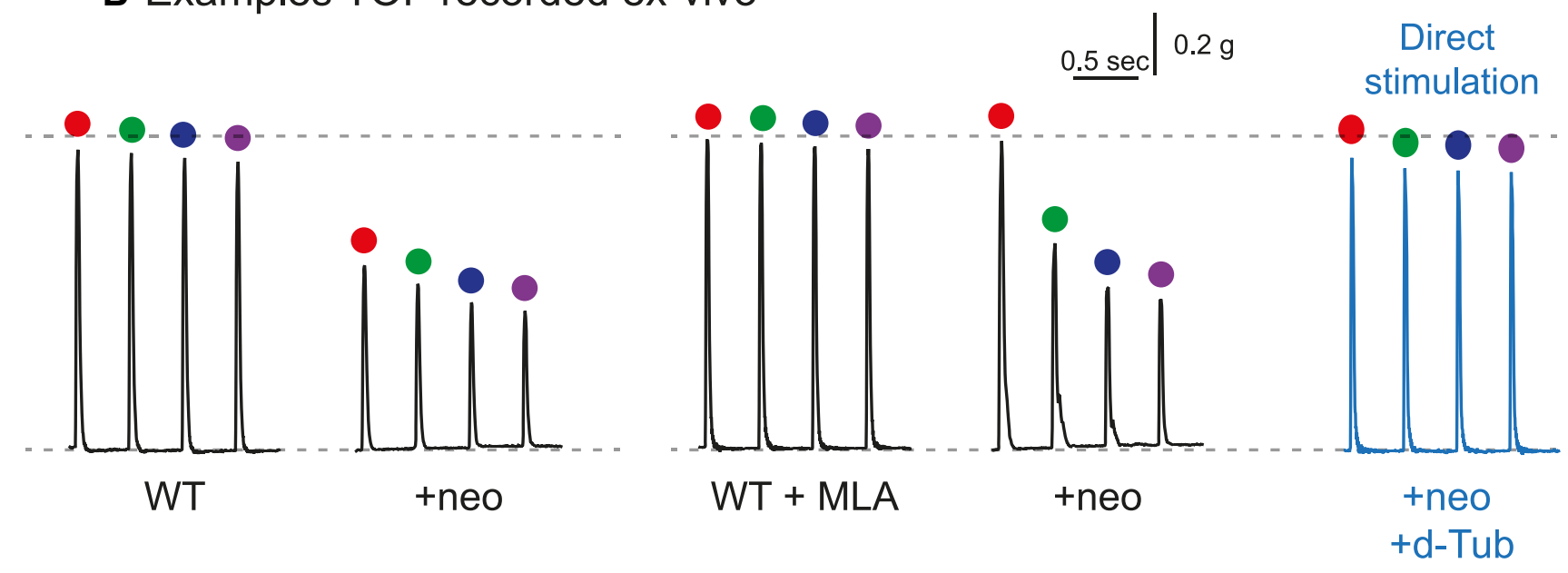

\section{Quantification of TOF amplitudes after neostigmine}

WT

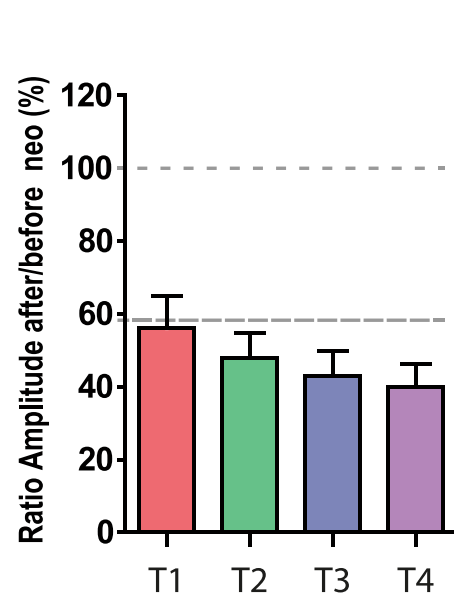

+ atropine

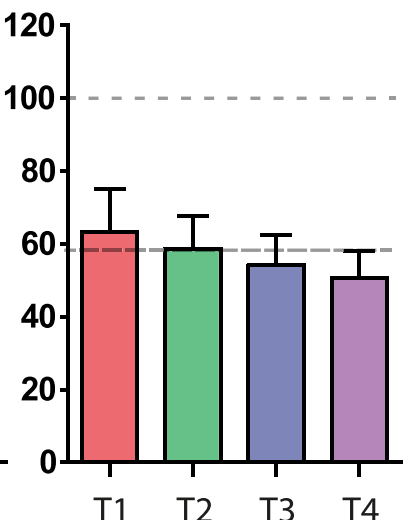

+ MLA

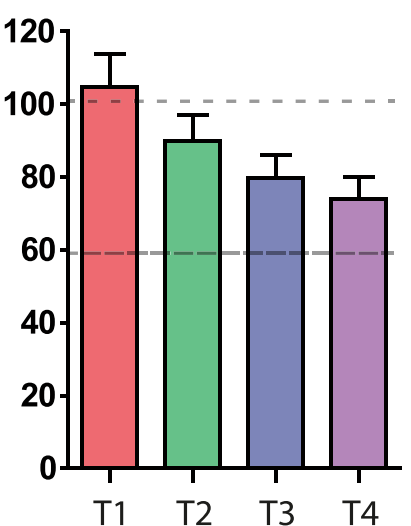

$\alpha 7 \mathrm{KO}$

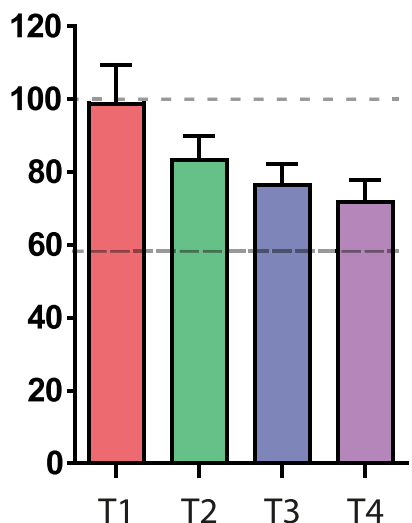

Figure 6. The reduction of the muscle contraction after inhibition of $\mathrm{AChE}$ and $\mathrm{BChE}$ is partially reversed by the block of $\alpha 7 \mathrm{nAChR}$. $A$, Experimental protocol. The phrenic-diaphragm preparation was mounted in the organ bath. The muscle is indirectly stimulated by the nerve and the twitch was quantified with a tension sensor. The muscle was stimulated each $30 \mathrm{~s}$ by $4 \mathrm{stimulations}$ at $2 \mathrm{~Hz}$. $B$, Example of the representative traces recorded before and 20 min after incubation with neostigmine ( $3 \mu \mathrm{M})$. C, Amplitude of $6 \mathrm{TOFs}$ obtained from in control condition, in atropine ( $0.1 \mu \mathrm{m})$, in MLA $(10 \mathrm{~nm})$, and in $\alpha 7 \mathrm{nAChR}$ KO mice. All values correspond to the mean of six successive TOFs in six different animals.

$\alpha 7 \mathrm{nAChR}$ at the TSC modulate the QC at the NMJ

Numerous experiments have shown that ACh acts on the nerve terminal and modulates its own release (Ciani and Edwards, 1963; Okamoto and Riker, 1969; Duncan and Publicover, 1979;
Dudel, 2007; Kupchik et al., 2011). Many investigators have applied exogenous agonists of AChR to reveal the presence of muscarinic and nicotinic AChRs (Miyamoto and Volle, 1974; Nikolsky et al., 1991, 2004; Vizi and Lendvai, 1997; Slutsky et al., 


\section{A Experimental protocol}
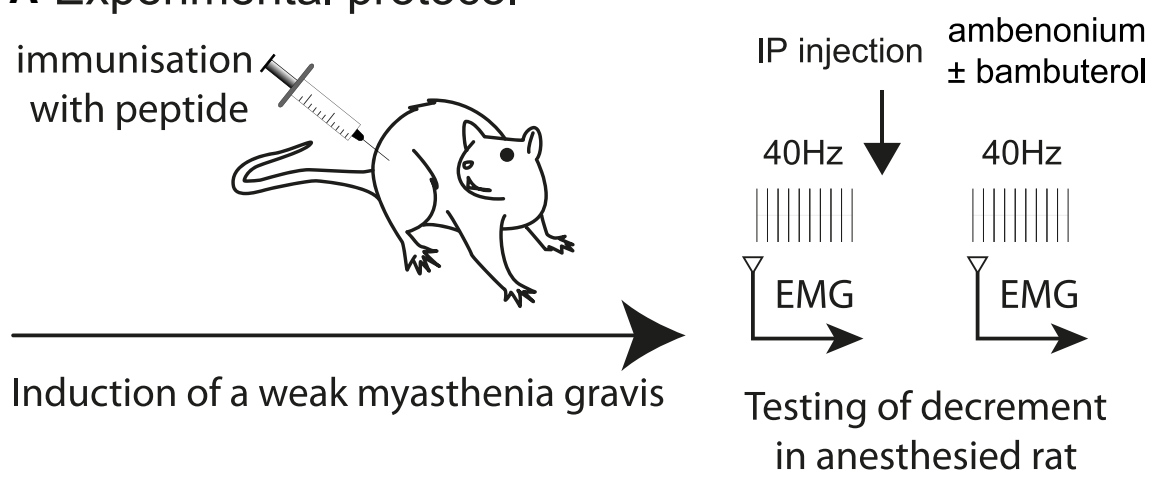

\section{B Examples of imAP in healthy and myasthenic rats}

Control

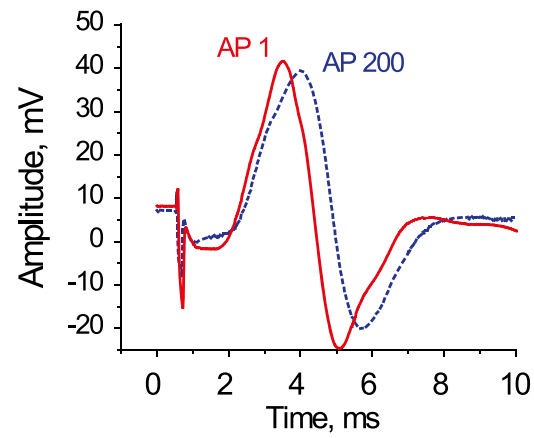

EAMG

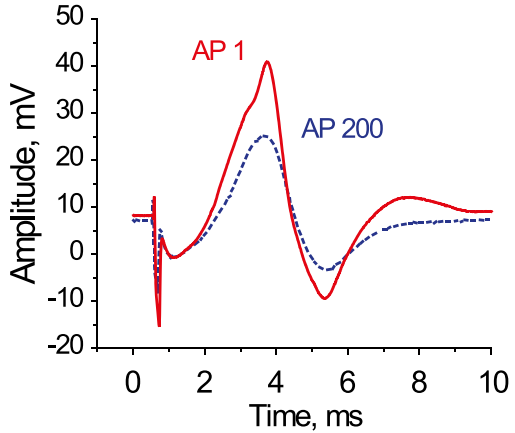

\section{Quantification of imAP amplitudes}

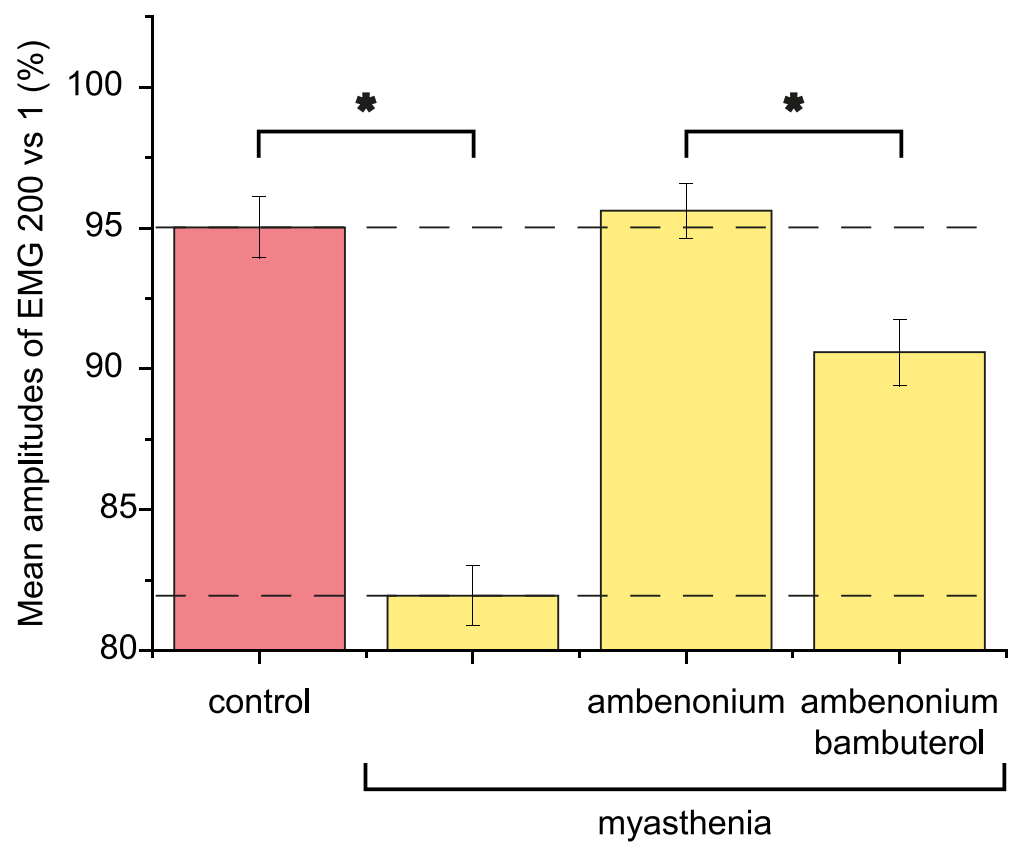

Figure 7. Rescue of MG rat with specific $A C h E$ inhibitor and the effect of subsequent BChE inhibition. $\boldsymbol{A}$, Experimental protocol. Rats were immunized with a peptide (sequence of main immunogenic region of rat muscle type AChR). EAMG was induced in 2 months. MG was tested by electromyography (EMG) recorded on leg of anesthetized rats. $\boldsymbol{B}$, Examples of integral muscle action potential (imAP) trace in intact (left) and at EAMG (right) muscles. The first nerve stimulation triggered a trace (AP1, red solid line). After $200 \mathrm{nerve}$ stimulations at $40 \mathrm{~Hz}$, the trace (AP200) is shown as a blue dashed line. $C$, The ratio of the amplitudes of AP200 versus AP1 was used for the quantification. The graph presents the percentage of AP200 versus AP1 in a control rat and in an EAMG rat before and after AChE inhibition (injection of $5 \mu \mathrm{g} / \mathrm{kg}$ ambenonium, i.p.) and subsequent BChE inhibition (injection of $0.2 \mathrm{mg} / \mathrm{kg} \mathrm{bambuterol,} \mathrm{i.p.)} \mathrm{(} n=5$, ${ }^{*} p<0.05$, unpaired Student's $t$ test). 


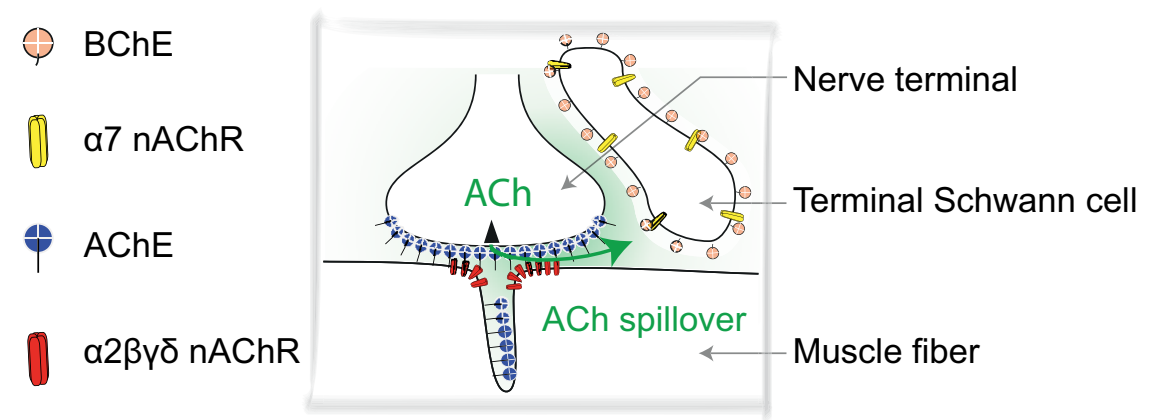

BChE inhibition
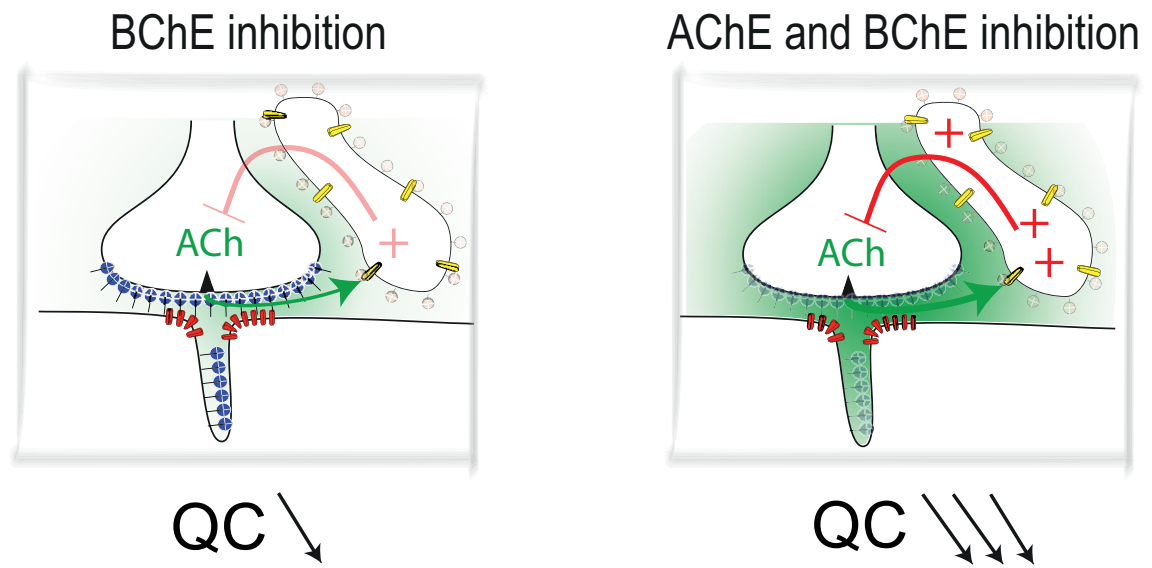

Figure 8. Diagram showing the signaling by ACh at the NMJ. Top, Localization of AChE, BChE, and $\alpha_{2} \beta \delta \varepsilon$ nAChRs and $\alpha 7$ nAChRs in the three domains of the NMJ: the axon terminal, the muscle fiber, and the extension of the TSC. AChE is mainly clustered (by $\mathrm{ColQ}$ ) in the primary and secondary cleft. It controls the activation of muscle $\alpha_{2} \beta \delta \varepsilon \mathrm{nAChRs}$. BChE is mainly anchored (by PRiMA) at the surface of the TSC and controls the activation of $\alpha 7 \mathrm{nAChRs} \mathrm{located} \mathrm{on} \mathrm{the} \mathrm{TSC.} \mathrm{Bottom,} \mathrm{Left,} \mathrm{When} \mathrm{BChE} \mathrm{is} \mathrm{inhibited,}$ the ACh that has escaped hydrolysis by the cleft AChE and the TSC BChE activates $\alpha 7 \mathrm{nAChRs}$ on the TSC. This induces a decrease of the $Q$ C. Right, When AChE and BChE are both inhibited, ACh spillover dramatically increases and the increased activation of $\alpha 7$ $\mathrm{nAChRs}$ produces a large decrease of the $\mathrm{QC}$. This counteracts the increased activation of muscle $\mathrm{nAChRs}$ by spilled over $\mathrm{ACh}$.

observations do not exclude that $\alpha 7$ nAChRs are also present at the postsynaptic membrane, where they were found in pathological conditions such as burning or immobilization (Lee et al., 2014).

How the TSCs may affect the release on the nerve terminal is not clear. There are many steps between the activation of $\alpha 7$ nAChR by the spillover of ACh and the reduction of $\mathrm{ACh}$ release at the nerve terminal. The initial step is likely to be the entry of calcium in the TSCs and the last one could be a decrease of calcium entry through inhibition of P/Q-type calcium channels of the nerve terminal. Between these two steps, a plausible hypothesis is the release by the TSCs of "gliotransmitters" such as glutamate, ATP, or adenosine because, in the CNS, these compounds have been shown to be released by glial cells, to have receptors on nerve terminals, and to interfere with voltage-dependent calcium channels (Araque et al., 2014), and there is evidence for similar phenomena in the peripheral nervous system (Castonguay et al., 2001). However, our main observations have been made minutes after the activation of $\alpha 7$ nAChRs so one cannot exclude slower cellular mechanisms, including the transcription and/or translation of new proteins or peptides.

The observation that long bursts of nerve stimulations $(30 \mathrm{~s}, 50 \mathrm{~Hz})$ can trigger calcium waves at the TSCs of mammalian NMJ was first made by Rochon et al.

2001; Minic et al., 2002). In some experiments, muscarinic agonists have inhibited ACh release from motor nerve terminals, whereas in others, ACh release was increased (Abbs and Joseph, 1981; Wessler et al., 1987; Arenson, 1991; Robitaille et al., 1997; Santafé et al., 2007). At the vertebrate NMJ, the activation of $\mathrm{m} 2$ $\mathrm{AChR}$ reduced the release, whereas the activation of $\mathrm{m} 1 / \mathrm{m} 3$ AChR facilitated the release (Slutsky et al., 2001; Minic et al., 2002; Oliveira et al., 2002, 2009; Dudel, 2007).

The regulation of ACh release at NMJs by nAChRs is less documented. The differential effects of nAChR blockers used by the anesthesiologists have been interpreted so far by their potential action on nAChRs. It was assumed that these receptors are localized at the nerve terminal (for review, see Vizi and Lendvai, 1999). Nicotine, a potent agonist of nAChRs, inhibits rhythmic activity of mouse NMJs (Balezina et al., 2006). This effect is prevented by $\alpha$-cobratoxin (a blocker of muscle and $\alpha 7 \mathrm{nAChRs)}$ and by apamin (a blocker of $\mathrm{Ca}^{2+}$-activated potassium channels). It was thus proposed that nicotine stimulates presynaptic nAChRs (presumably $\alpha 7$ ) that activate $\mathrm{Ca}^{2+}$-activated potassium channels. However, previous experiments failed to find $\alpha$-bungarotoxin ( $\alpha 7 \mathrm{nAChRs}$ ligand in neurons) on the nerve terminal (Jones and Salpeter, 1983) and our results suggest that $\alpha 7 \mathrm{nAChRs}$ are localized at the TSC. We found a weak labeling with specific antibodies colocalized with S100 (a well established TSC marker). This labeling was absent in $\alpha 7 \mathrm{KO}$ mice. Calcium waves in the TSC triggered by long bursts of nerve stimulations were abolished by $10 \mathrm{~nm}$ MLA (a specific blocker of $\alpha 7 \mathrm{nAChR}$ ). These
(2001). These calcium waves were blocked by $20 \mu \mathrm{M}$ atropine and were therefore attributed to the activation of muscarinic receptors (mAChRs). However, after 25 min of recovery, long bursts of nerve stimulations were not able to generate new calcium waves (Rochon et al., 2001). In contrast, with a similar pattern of nerve stimulation $(120 \mathrm{~s}, 20 \mathrm{~Hz})$, we triggered repetitive calcium waves in the TSCs when $30 \mathrm{~min}$ recovery periods were allowed. Moreover, we found that the second waves were abolished by MLA. The design of the experiments likely explains this discrepancy. Calcium imaging at the NMJ requires that muscle contraction be abolished. To prevent muscle contraction, we used $\mu$-conotoxin GIIIB, a blocker of the muscle voltage-gated sodium channel that does not interfere with $\alpha 7 \mathrm{nAChRs}$ and muscle nAChRs. In contrast, Rochon et al. (2001) (see also Todd et al., 2007; Rousse et al., 2010) blocked the contraction using D-tubocurarine or $\alpha$-bungarotoxin, which are known to block $\alpha 7$ nAChRs (Alexander et al., 2013), and applied atropine at $20 \mu \mathrm{M}$, a concentration that blocks mAChRs, but also $\alpha 7$ nAChRs (Zwart and Vijverberg, 1997; González-Rubio et al., 2006). $\alpha 7$ nAChRs were thus likely to be blocked in these experiments and thus prevented the generation of a second wave of calcium.

The presence of functional $\alpha 7 \mathrm{nAChRs}$ was previously shown on astrocytes in cell culture (Sharma and Vijayaraghavan, 2001) and on NG2 cells in brain slices (Vélez-Fort et al., 2009). When $\alpha 7 \mathrm{nAChRs}$ are activated by ACh they induce calcium entry, but their function remains elusive. We found for the first time here that activation of extrasynaptic $\alpha 7 \mathrm{nAChRs}$ depresses ACh re- 
lease. It remains to be determined in which physiological conditions ACh activates these $\alpha 7 \mathrm{nAChRs}$. It is tempting to propose that $\alpha 7 \mathrm{nAChRs}$ play the role of ACh sensor outside of the synaptic cleft at the NMJ. In the context of synaptic homeostasis, it represents the first sensor that detects the excess of neurotransmitter (Davis, 2013).

\section{BChE, a forgotten enzyme}

The mammalian cholinesterases include two well known closely related enzymes, AChE (E.C. 3.1.1.7) and BChE (E.C. 3.1.1.8), that hydrolyze ACh efficiently. The participation of BChE in synaptic transmission has been completely ignored until now (Johnson and Moore, 2012). We have now revealed that BChE localized on the TSC regulates the activation of $\alpha 7 \mathrm{nAChRs}$, but not the activation of the muscle nAChRs. We found that BChE is anchored by PRiMA, the small transmembrane protein required for the maturation of AChE in the brain (Perrier et al., 2002; Dobbertin et al., 2009). This localization of BChE/PRiMA at the TSC contrasts with the localization of AChE mainly anchored by ColQ in the extracellular matrix of the synaptic cleft (Younkin et al., 1982; Bernard et al., 2011). We can speculate that one of the physiological functions of $\mathrm{BChE}$ is to control the spillover of $\mathrm{ACh}$ around the TSC and thus the activation of AChRs localized outside of the synaptic cleft. Our results suggest that the spillover of ACh in the CNS described previously (Lamotte d'Incamps et al., 2012) also exists at the NMJ despite the high density of AChE.

\section{Use of specific versus nonspecific AChE inhibitors}

The use of specific (AChE) or nonspecific (AChE and BChE) inhibitors to treat myasthenia was described previously, but the rationale to select one or the other was not clear (Komloova et al., 2010). The pharmacokinetics of specific AChE inhibitors is obviously different from the nonspecific inhibitors because BChE is highly abundant in the serum and in several tissues. Indeed, $\mathrm{BChE}$ is a scavenger of the nonspecific inhibitors and decreases their active concentration. Moreover, the level of BChE is variable in the human population due to the genetic polymorphism (Benyamin et al., 2011) and to the eventual previous exposure of each individual to drugs and toxins detoxified by BChE (Masson and Lockridge, 2010). Therefore, the nonspecific inhibitors are more difficult to use because they bind to variable levels of BChE, a problem that does not affect the specific AChE inhibitors. We provide here direct evidence for an additional advantage of specific AChE inhibitors over nonspecific inhibitors to improve the muscle function in the treatment of MG. The AChE inhibition increases the lifetime of ACh molecules in the synaptic cleft and thus the number of AChRs opened by ACh, allowing EPP amplitude to reach the threshold of AP and thus to trigger muscle fiber twitch. If BChE is also inhibited, the increase of the EPP is expected to be limited by the negative feedback loop that includes $\alpha 7 \mathrm{nAChR}$ on the TSC: fewer quanta of ACh are released and the amplitude of the EPP is reduced.

In human surgery, the muscle contraction is blocked with nondepolarizing muscle relaxant (NDMR) agents (competitive antagonists of muscle nAChR). The reversion of the block is a critical period in which NDMRs must unbind the nAChR (Srivastava and Hunter, 2009). The most common method to displace the competitive antagonist is the increase of ACh concentration by inhibition of AChE. Based on empirical practices, neostigmine, the most common used AChE inhibitor (a carbamatenonspecific AChE and BChE inhibitor), must be applied only when the synaptic transmission has recovered in a part of the fiber, otherwise the muscle enters in a longer block. It is tempting to propose that specific AChE inhibitors would be more efficient because the risk of triggering the depression of the release by the inhibition of BChE would be reduced.

\section{References}

Abbs ET, Joseph DN (1981) The effects of atropine and oxotremorine on acetylcholine release in rat phrenic nerve-diaphragm preparations. $\mathrm{Br} \mathrm{J}$ Pharmacol 73:481-483. CrossRef Medline

Alexander SP, Benson HE, Faccenda E, Pawson AJ, Sharman JL, Spedding M, Peters JA, Harmar AJ; CGTP Collaborators (2013) The concise guide to pharmacology 2013/14: enzymes. Br J Pharmacol 170:1797-1867. CrossRef Medline

Ali HH, Wilson RS, Savarese JJ, Kitz RJ (1975) The effect of tubocurarine on indirectly elicited train-of-four muscle response and respiratory measurements in humans. Br J Anaesth 47:570-574. CrossRef Medline

Araque A, Carmignoto G, Haydon PG, Oliet SH, Robitaille R, Volterra A (2014) Gliotransmitters travel in time and space. Neuron 81:728-739. CrossRef Medline

Arenson MS (1991) The effects of muscarine and atropine reveal that inhibitory autoreceptors are present on frog motor nerve terminals but are not activated during transmission. Naunyn Schmiedebergs Arch Pharmacol 343:128-133. CrossRef Medline

Auld DS, Robitaille R (2003) Glial cells and neurotransmission: an inclusive view of synaptic function. Neuron 40:389-400. CrossRef Medline

Baggi F, Annoni A, Ubiali F, Longhi R, Mantegazza R, Cornelio F, Antozzi C (2003) Effect on $\mathrm{T}$ cell recognition and immunogenicity of alaninesubstituted peptides corresponding to 97-116 sequence of the rat AChR $\alpha$-subunit. Ann N Y Acad Sci 998:395-398. CrossRef Medline

Balezina OP, Fedorin VV, Gaidukov AE (2006) Effect of nicotine on neuromuscular transmission in mouse motor synapses. Bull Exp Biol Med 142: 17-21. CrossRef Medline

Benyamin B, Middelberg RP, Lind PA, Valle AM, Gordon S, Nyholt DR, Medland SE, Henders AK, Heath AC, Madden PA, Visscher PM, O'Connor DT, Montgomery GW, Martin NG, Whitfield JB (2011) GWAS of butyrylcholinesterase activity identifies four novel loci, independent effects within $\mathrm{BCHE}$ and secondary associations with metabolic risk factors. Hum Mol Genet 20:4504-4514. CrossRef Medline

Bernard V, Girard E, Hrabovska A, Camp S, Taylor P, Plaud B, Krejci E (2011) Distinct localization of collagen Q and PRiMA forms of acetylcholinesterase at the neuromuscular junction. Mol Cell Neurosci 46:272281. CrossRef Medline

Blondet B, Carpentier G, Ferry A, Chatonnet A, Courty J (2010) Localization of butyrylcholinesterase at the neuromuscular junction of normal and acetylcholinesterase knockout mice. J Histochem Cytochem 58: 1075-1082. CrossRef Medline

Bonansco C, Couve A, Perea G, Ferradas CÁ, Roncagliolo M, Fuenzalida M (2011) Glutamate released spontaneously from astrocytes sets the threshold for synaptic plasticity. Eur J Neurosci 33:1483-1492. CrossRef Medline

Castonguay A, Robitaille R (2001) Differential regulation of transmitter release by presynaptic and glial $\mathrm{Ca}^{2+}$ internal stores at the neuromuscular synapse. J Neurosci 21:1911-1922. Medline

Ciani S, Edwards C (1963) The effect of acetylcholine on neuromuscular transmission in the frog. J Pharmacol Exp Ther 142:21-23. Medline

Davis GW (2013) Homeostatic signaling and the stabilization of neural function. Neuron 80:718-728. CrossRef Medline

Davis R, Koelle GB (1967) Electron microscopic localization of acetylcholinesterase and nonspecific cholinesterase at the neuromuscular junction by the gold-thiocholine and gold-thiolacetic acid methods. J Cell Biol 34:157-171. CrossRef Medline

De Paola V, Arber S, Caroni P (2003) AMPA receptors regulate dynamic equilibrium of presynaptic terminals in mature hippocampal networks. Nat Neurosci 6:491-500. CrossRef Medline

Dobbertin A, Hrabovska A, Dembele K, Camp S, Taylor P, Krejci E, Bernard V (2009) Targeting of acetylcholinesterase in neurons in vivo: a dual processing function for the proline-rich membrane anchor subunit and the attachment domain on the catalytic subunit. J Neurosci 29:45194530. CrossRef Medline

Dudel J (2007) The time course of transmitter release in mouse motor nerve terminals is differentially affected by activation of muscarinic M1 or M2 receptors. Eur J Neurosci 26:2160-2168. CrossRef Medline

Duncan CJ, Publicover SJ (1979) Inhibitory effects of cholinergic agents on 
the release of transmitter at the frog neuromuscular junction. J Physiol 294:91-103. Medline

González-Rubio JM, García de Diego AM, Egea J, Olivares R, Rojo J, Gandía L, García AG, Hernández-Guijo JM (2006) Blockade of nicotinic receptors of bovine adrenal chromaffin cells by nanomolar concentrations of atropine. Eur J Pharmacol 535:13-24. CrossRef Medline

Hartzell HC, Kuffler SW, Yoshikami D (1975) Post-synaptic potentiation: interaction between quanta of acetylcholine at the skeletal neuromuscular synapse. J Physiol 251:427-463. Medline

Johnson G, Moore SW (2012) Why has butyrylcholinesterase been retained? Structural and functional diversification in a duplicated gene. Neurochem Int 61:783-797. CrossRef Medline

Jones SW, Salpeter MM (1983) Absence of [125I] alpha-bungarotoxin binding to motor nerve terminals of frog, lizard and mouse muscle. J Neurosci 3:326-331. Medline

Kalashnyk OM, Gergalova GL, Komisarenko SV, Skok MV (2012) Intracellular localization of nicotinic acetylcholine receptors in human cell lines. Life Sci 91:1033-1037. CrossRef Medline

Komloova M, Musilek K, Dolezal M, Gunn-Moore F, Kuca K (2010) Structure-activity relationship of quaternary acetylcholinesterase inhibitors-outlook for early myasthenia gravis treatment. Curr Med Chem 17:1810-1824. CrossRef Medline

Kupchik YM, Barchad-Avitzur O, Wess J, Ben-Chaim Y, Parnas I, Parnas H (2011) A novel fast mechanism for GPCR-mediated signal transduction-control of neurotransmitter release. J Cell Biol 192:137-151. CrossRef Medline

Lamotte d'Incamps B, Krejci E, Ascher P (2012) Mechanisms shaping the slow nicotinic synaptic current at the motoneuron-Rrenshaw cell synapse. J Neurosci 32:8413-8423. CrossRef Medline

Lee S, Yang HS, Sasakawa T, Khan MA, Khatri A, Kaneki M, Martyn JA (2014) Immobilization with atrophy induces de novo expression of neuronal nicotinic $\alpha 7$ acetylcholine receptors in muscle contributing to neurotransmission. Anesthesiology 120:76-85. Medline

Masson P, Lockridge O (2010) Butyrylcholinesterase for protection from organophosphorus poisons: catalytic complexities and hysteretic behavior. Arch Biochem Biophys 494:107-120. CrossRef Medline

Massoulié J, Perrier N, Noureddine H, Liang D, Bon S (2008) Old and new questions about cholinesterases. Chem Biol Interact 175:30-44. CrossRef Medline

Minic J, Molgó J, Karlsson E, Krejci E (2002) Regulation of acetylcholine release by muscarinic receptors at the mouse neuromuscular junction depends on the activity of acetylcholinesterase. Eur J Neurosci 15:439448. CrossRef Medline

Minic J, Chatonnet A, Krejci E, Molgó J (2003) Butyrylcholinesterase and acetylcholinesterase activity and quantal transmitter release at normal and acetylcholinesterase knockout mouse neuromuscular junctions. Br J Pharmacol 138:177-187. CrossRef Medline

Miyamoto MD, Volle RL (1974) Enhancement by carbachol of transmitter release from motor nerve terminals. Proc Natl Acad Sci U S A 71:14891492. CrossRef Medline

Mrvova K, Obzerova L, Girard E, Krejci E, Hrabovska A (2013) Monoclonal antibodies to mouse butyrylcholinesterase. Chem Biol Interact 203:348353. CrossRef Medline

Nicolet Y, Lockridge O, Masson P, Fontecilla-Camps JC, Nachon F (2003) Crystal structure of human butyrylcholinesterase and of its complexes with substrate and products. J Biol Chem 278:41141-41147. CrossRef Medline

Nikolsky EE, Bukharaeva EA, Strunsky EG, Vyskocil F (1991) Depression of miniature endplate potential frequency by acetylcholine and its analogues in frog. Br J Pharmacol 104:1024-1032. CrossRef Medline

Nikolsky EE, Vyskocil F, Bukharaeva EA, Samigullin D, Magazanik LG (2004) Cholinergic regulation of the evoked quantal release at frog neuromuscular junction. J Physiol 560:77-88. CrossRef Medline

Okamoto M, Riker WF Jr (1969) Motor nerve terminals as the site of initial functional changes after denervation. J Gen Physiol 53:70-80. CrossRef Medline

Oliveira L, Timóteo MA, Correia-de-Sá P (2002) Modulation by adenosine of both muscarinic M1-facilitation and M2-inhibition of $\left[{ }^{3} \mathrm{H}\right]-$ acetylcholine release from the rat motor nerve terminals. Eur J Neurosci 15:1728-1736. CrossRef Medline

Oliveira L, Timóteo MA, Correia-de-Sá P (2009) Negative crosstalk between M1 and M2 muscarinic autoreceptors involves endogenous adenosine activating A1 receptors at the rat motor endplate. Neurosci Lett 459:127-131. CrossRef Medline

Perrier AL, Massoulié J, Krejci E (2002) PRiMA: the membrane anchor of acetylcholinesterase in the brain. Neuron 33:275-285. CrossRef Medline

Plaud B, Debaene B, Donati F, Marty J (2010) Residual paralysis after emergence from anesthesia. Anesthesiology 112:1013-1022. CrossRef Medline

Reynolds ML, Woolf CJ (1992) Terminal Schwann cells elaborate extensive processes following denervation of the motor endplate. J Neurocytol 21: 50-66. CrossRef Medline

Robitaille R, Jahromi BS, Charlton MP (1997) Muscarinic $\mathrm{Ca}^{2+}$ responses resistant to muscarinic antagonists at perisynaptic Schwann cells of the frog neuromuscular junction. J Physiol 504:337-347. CrossRef Medline

Rochon D, Rousse I, Robitaille R (2001) Synapse-glia interactions at the mammalian neuromuscular junction. J Neurosci 21:3819-3829. Medline

Rousse I, St-Amour A, Darabid H, Robitaille R (2010) Synapse-glia interactions are governed by synaptic and intrinsic glial properties. Neuroscience 167:621-632. CrossRef Medline

Santafé MM, Lanuza MA, Garcia N, Tomàs M, Tomàs J (2007) Coupling of presynaptic muscarinic autoreceptors to serine kinases in low and high release conditions on the rat motor nerve terminal. Neuroscience 148: 432-440. CrossRef Medline

Sharma G, Vijayaraghavan S (2001) Nicotinic cholinergic signaling in hippocampal astrocytes involves calcium-induced calcium release from intracellular stores. Proc Natl Acad Sci U S A 98:4148-4153. CrossRef Medline

Slutsky I, Silman I, Parnas I, Parnas H (2001) Presynaptic M(2) muscarinic receptors are involved in controlling the kinetics of ACh release at the frog neuromuscular junction. J Physiol 536:717-725. CrossRef Medline

Srivastava A, Hunter JM (2009) Reversal of neuromuscular block. Br J Anaesth 103:115-129. CrossRef Medline

Todd KJ, Auld DS, Robitaille R (2007) Neurotrophins modulate neuronglia interactions at a vertebrate synapse. Eur J Neurosci 25:1287-1296. CrossRef Medline

Todd KJ, Darabid H, Robitaille R (2010) Perisynaptic glia discriminate patterns of motor nerve activity and influence plasticity at the neuromuscular junction. J Neurosci 30:11870-11882. CrossRef Medline

Vélez-Fort M, Audinat E, Angulo MC (2009) Functional $\alpha 7$-containing nicotinic receptors of NG2-expressing cells in the hippocampus. Glia 57: 1104-1114. CrossRef Medline

Vincent A (2010) Autoimmune channelopathies: well-established and emerging immunotherapy-responsive diseases of the peripheral and central nervous systems. J Clin Immunol 30:S97-S102. CrossRef Medline

Vizi ES, Lendvai B (1997) Side effects of nondepolarizing muscle relaxants: relationship to their antinicotinic and antimuscarinic actions. Pharmacol Ther 73:75-89. CrossRef Medline

Vizi ES, Lendvai B (1999) Modulatory role of presynaptic nicotinic receptors in synaptic and non-synaptic chemical communication in the central nervous system. Brain Res Rev 30:219-235. CrossRef Medline

Wessler I, Karl M, Mai M, Diener A (1987) Muscarine receptors on the rat phrenic nerve, evidence for positive and negative muscarinic feedback mechanisms. Naunyn Schmiedebergs Arch Pharmacol 335:605-612. CrossRef Medline

Wood SJ, Slater CR (1995) Action potential generation in rat slow- and fast-twitch muscles. J Physiol 486:401-410. Medline

Younkin SG, Rosenstein C, Collins PL, Rosenberry TL (1982) Cellular localization of the molecular forms of acetylcholinesterase in rat diaphragm. J Biol Chem 257:13630-13637. Medline

Zwart R, Vijverberg HP (1997) Potentiation and inhibition of neuronal nicotinic receptors by atropine: competitive and noncompetitive effects. Mol Pharmacol 52:886-895. CrossRef Medline 